Review

\title{
Iron Deficiency in Heart Failure: Mechanisms and Pathophysiology
}

\author{
Ridha I. S. Alnuwaysir (), Martijn F. Hoes $\mathbb{C}^{\circ}$, Dirk J. van Veldhuisen $\mathbb{(}^{(}$, Peter van der Meer \\ and Niels Grote Beverborg *
}

check for

updates

Citation: Alnuwaysir, R.I.S.; Hoes, M.F.; van Veldhuisen, D.J.; van der Meer, P.; Grote Beverborg, N. Iron Deficiency in Heart Failure: Mechanisms and Pathophysiology. J. Clin. Med. 2022, 11, 125. https:// doi.org/10.3390/jcm11010125

Academic Editors:

Josep Comín-Colet and

Andrea Frustaci

Received: 25 November 2021

Accepted: 22 December 2021

Published: 27 December 2021

Publisher's Note: MDPI stays neutral with regard to jurisdictional claims in published maps and institutional affiliations.

Copyright: () 2021 by the authors. Licensee MDPI, Basel, Switzerland. This article is an open access article distributed under the terms and conditions of the Creative Commons Attribution (CC BY) license (https:// creativecommons.org/licenses/by/ $4.0 /)$.

\author{
Department of Cardiology, University Medical Center Groningen, University of Groningen, P.O. Box 30.001, \\ 9700 RB Groningen, The Netherlands; r.i.s.alnuwaysir@umcg.nl (R.I.S.A.); m.hoes@umcg.nl (M.F.H.); \\ d.j.van.veldhuisen@umcg.nl (D.J.v.V.); p.van.der.meer@umcg.nl (P.v.d.M.) \\ * Correspondence: n.grote.beverborg@umcg.nl
}

\begin{abstract}
Iron is an essential micronutrient for a myriad of physiological processes in the body beyond erythropoiesis. Iron deficiency (ID) is a common comorbidity in patients with heart failure (HF), with a prevalence reaching up to $59 \%$ even in non-anaemic patients. ID impairs exercise capacity, reduces the quality of life, increases hospitalisation rate and mortality risk regardless of anaemia. Intravenously correcting ID has emerged as a promising treatment in HF as it has been shown to alleviate symptoms, improve quality of life and exercise capacity and reduce hospitalisations. However, the pathophysiology of ID in HF remains poorly characterised. Recognition of ID in HF triggered more research with the aim to explain how correcting ID improves HF status as well as the underlying causes of ID in the first place. In the past few years, significant progress has been made in understanding iron homeostasis by characterising the role of the iron-regulating hormone hepcidin, the effects of ID on skeletal and cardiac myocytes, kidneys and the immune system. In this review, we summarise the current knowledge and recent advances in the pathophysiology of ID in heart failure, the deleterious systemic and cellular consequences of ID.
\end{abstract}

Keywords: iron deficiency; iron metabolism; heart failure; pathophysiology

\section{Introduction}

Heart failure (HF) is a complex syndrome in which the heart fails to circulate the required amount of blood and nutrients to meet the body's demands [1]. Despite substantial advances in prevention and treatment strategies of HF, it continues to represent a huge burden on public health worldwide, with an exceptionally high mortality rate reaching up to $75 \%$ at 5 years [2]. This makes HF as 'malignant' as some types of cancer [3,4]. Multimorbidity in the ageing population of HF is becoming increasingly frequent, with almost half of the patients presenting with five or more noncardiac comorbidities [4,5]. The presence of comorbidities increases the complexity of treating HF and impairs quality of life and clinical outcomes [6,7]. Therefore, management of comorbidities in addition to the mainstay therapies of HF constitutes a crucial aspect of HF treatment [8].

Iron deficiency (ID) and anaemia are among the most frequently observed comorbidities in HF, and both are independently associated with worse clinical status and outcomes [9-11]. Not only the presence of these comorbidities has been associated with worse prognosis, but also the severity, with advancing severity associated with higher mortality rates [10]. Although ID has traditionally been linked with anaemia, commonly referred to as iron deficiency anaemia (IDA), the two conditions do not necessarily coexist [12]. In fact, ID is poorly linked with red cell indices in HF, indicating that ID in these patients should be seen independently of erythropoietic status [13].

ID is substantially more prevalent than anaemia in $\mathrm{HF}$, with a prevalence reaching up to $59 \%$ even in non-anaemic ambulatory HF patients [10,14-17]. In acute HF, the 
prevalence of ID among non-anaemic patients is even higher at $57 \%$ in men and $79 \%$ in women [18]. Iron status, independently of haemoglobin $(\mathrm{Hb})$ levels, is associated with reduced exercise capacity, impaired quality of life and increased risk of death and hospital (re-)admissions [12,14,16,19-21]. Intravenously correcting ID was shown to improve quality of life, exercise performance and symptoms regardless of $\mathrm{Hb}$ levels [22-25]. These observations underscore the crucial role of iron beyond erythropoiesis [26]. Additionally, although the recent AFFIRM-AHF study statistically missed its primary endpoint (i.e., combined recurrent hospitalisations or cardiovascular mortality), administering intravenous (IV) iron in patients with acute HF significantly reduced recurrent hospitalisations [27,28]. The evidence on mortality is yet to be ascertained [29].

The mechanisms leading to these clinical benefits, as well as the underlying causes that led to ID in the first place, remain poorly characterised. Not understanding the pathomechanisms leading to ID might potentially result in missed diagnoses (i.e., underlying gastro-intestinal malignancies, malnutrition) and undertreatment [30,31]. Recently, ID was identified as a key element involved in the pathophysiology of HF and its progression, suggesting that ID might be more than merely a comorbidity in HF [32-34]. In this review, we aim to summarise the current understanding of the pathophysiology of ID as well as its biological repercussions in patients with HF. Moreover, the latest progress in mechanistic studies on the potential role of IV iron supplementation is outlined.

\subsection{Physiologic Roles and Regulation of Iron}

Iron is an essential cofactor for the normal functioning of many enzymes participating in vital cellular and organismal functions, making it indispensable for every living cell [35-37]. In addition to its important role in oxygen transport and storage as a constituent of hemoglobin and myoglobin respectively, iron is crucial for many enzymes and proteins involved in oxidative metabolic processes (e.g., mitochondrial respiratory chain, oxidative enzymes and protection against oxidative stress), microRNA biogenesis, the function of the thyroid gland, central nervous system and immune system [35,36,38]. Furthermore, iron is crucial for the synthesis and degradation of proteins, lipids (e.g., $\beta$-oxidation of fatty acids), carbohydrates, DNA and RNA [38-42]. Of note, iron is particularly important for cells either with high energy demand (cardiomyocytes, hepatocytes, neurons, renal and skeletal cells) or high mitogenic activity (e.g., haematopoietic and immune cells) [26,43]. Accordingly, these cells are more sensitive to ID [26]. An overview of the functions and proteins that require iron are outlined in Figure 1 and Table 1 [43-45], respectively.

Table 1. Overview of proteins that require iron to function properly.

\begin{tabular}{|c|c|}
\hline Function & Protein \\
\hline Oxygen transport & Hemoglobin \\
\hline Oxygen storage & Myoglobin \\
\hline Lipid and cholesterol biosynthesis & $\begin{array}{c}\text { NADPH-cytochrome P450 reductase, fatty acid } \\
\text { desaturases, cytochrome P-450 subfamily } 51 \\
\text { and Cytochrome P450 Family } 7 \text { Subfamily A } \\
\text { Member } 1\end{array}$ \\
\hline Oxygen sensing and regulation of hypoxia & Hypoxia-inducible factor prolyl hydroxylases \\
\hline $\begin{array}{c}\text { Synthesis catecholamines and } \\
\text { neurotransmitters }\end{array}$ & $\begin{array}{l}\text { Tryptophan hydroxylase, tyrosine hydroxylase, } \\
\text { monoamine oxidase and aldehyde oxidase }\end{array}$ \\
\hline $\begin{array}{l}\text { Host defence, inflammation and production of } \\
\text { nitric oxide }\end{array}$ & $\begin{array}{c}\text { Myeloperoxidase, NADPH oxidase, } \\
\text { indoleamine 2,3- dioxygenase, nitric oxide } \\
\text { synthase and lipoxygenases }\end{array}$ \\
\hline DNA synthesis, replication and repair & $\begin{array}{c}\text { Ribonucleotide reductases, DNA polymerases, } \\
\text { DNA glycolsylases, DNA primases, DNA } \\
\text { helicasess and DNA endonucleases. } \\
\text { Dihydropyrimidine dehydrogenas }\end{array}$ \\
\hline
\end{tabular}


Table 1. Cont.

\begin{tabular}{cc}
\hline Function & Protein \\
\hline Collagen synthesis & $\begin{array}{c}\text { Proline hydroxylase } \\
\text { Electron transport and respiratory chain } \\
\text { Adrenoxin }\end{array}$ \\
Cytochrome C oxidase, Cytochrome b, \\
NADH dehydrogenase, aconitase, citrate \\
synthase, Succinyl dehydogease, cytochrome \\
reductase, Complex I-III, rieske protein, NADH \\
ferrocyanide oxidoreductase
\end{tabular}

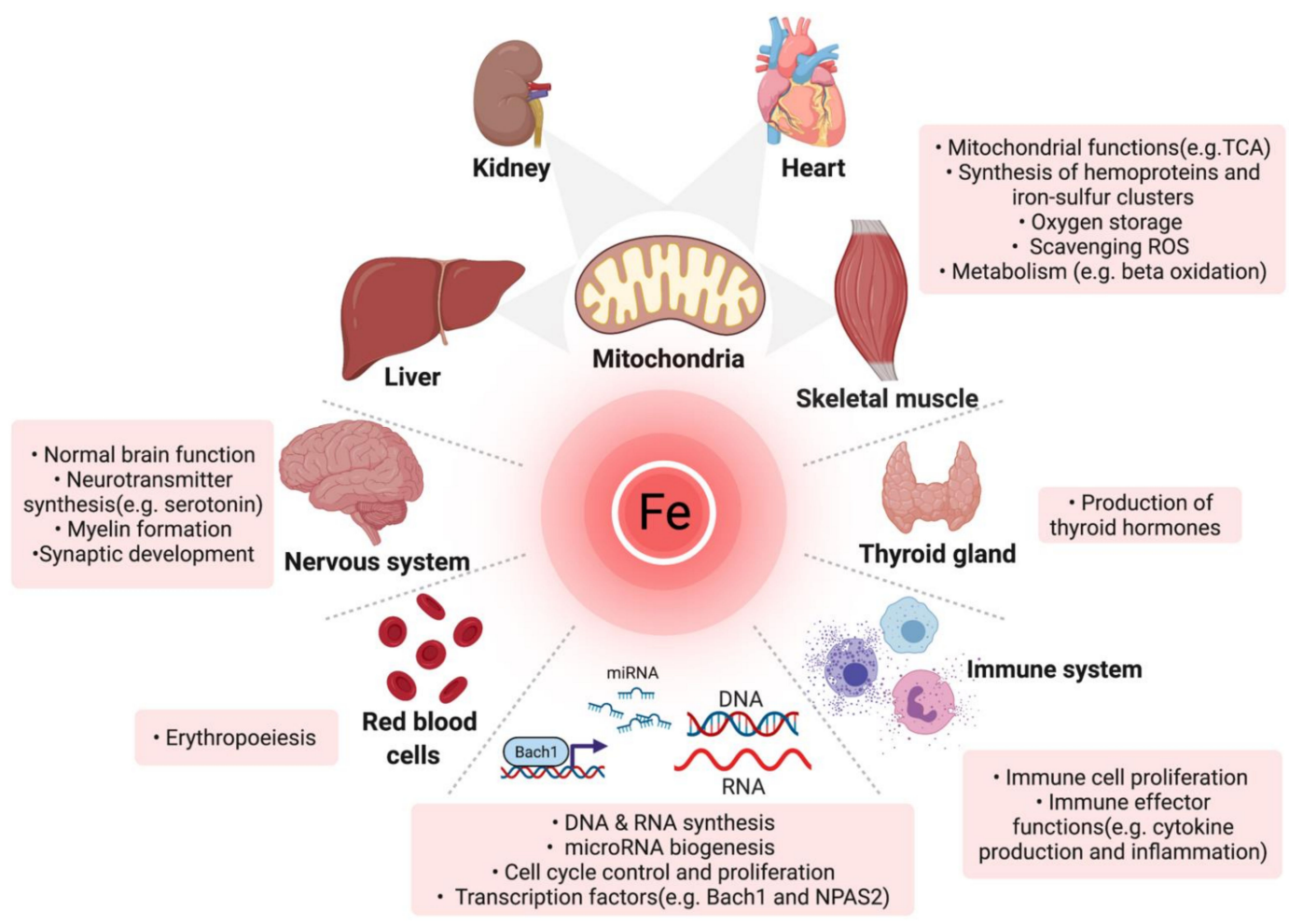

Figure 1. Overview of the multifaceted roles of iron in diverse organs and molecular processes. TCA: tricarboxylic acid cycle; miRNA: microRNA, ROS: reactive oxygen species (Created with BioRender.com, accessed on 24 November 2021). 
Besides its crucial roles in the body, iron is a potentially harmful element to cells given its chemical reactivity and its propensity to generate reactive oxygen species through participating in Fenton's reaction [35,43]. Iron is almost always linked to either ferritin intracellularly or extracellularly to transferrin as free iron ions are toxic [35]. In addition, iron status is tightly regulated both systematically by hepcidin and cellularly through iron-regulatory proteins. A detailed description of iron metabolism is beyond the scope of this review. A comprehensive overview of cellular and systemic iron metabolism can be found elsewhere [45-48].

\subsection{Definition of Iron Deficiency}

ID ensues when iron supply is insufficient to meet the body's needs or to cover the iron lost physiologically or pathologically [39]. ID may manifest itself in two distinct forms with intertwined pathophysiology, namely functional and absolute ID. Absolute ID (AID) reflects depleted iron stores, while functional ID (FID) is characterised by reduced availability of iron despite sufficient or overly abundant iron stores due to suboptimal iron trafficking induced by hepcidin. It is crucial to note that studies in HF differ in defining ID [10,49-51]. The most widely used definition of ID, which is also adopted by the European Society of Cardiology (ESC), is a ferritin level $<100 \mu \mathrm{g} / \mathrm{L}$ (reflecting AID) or ferritin (100 to $300 \mu \mathrm{g} / \mathrm{L}$ ) with a transferrin saturation (TSAT) $<20 \%$ (reflecting FID) [8]. This definition of ID has, however, been criticised as it has never been validated against a gold standard and remains a subject of considerable debate, especially in patients with acute HF [49,50,52-55].

The ESC definition of ID (also called the FAIR-HF definition [22]) is limited by relying heavily on ferritin levels, thereby labelling patients with TSAT $\leq 20 \%$, but a ferritin $>300 \mu \mathrm{g} / \mathrm{mL}$ as iron sufficient, while labelling those with isolated hypoferritinaemia (ferritin $<100 \mu \mathrm{g} / \mathrm{mL}$ with a TSAT $>20 \%$ ) as iron deficient. This latter category was found to be iron sufficient when compared to bone marrow staining, the golden standard for diagnosing ID [54]. Although ferritin is one of the most widely used biomarkers to detect iron deficiency [56], serum ferritin levels can be profoundly influenced by several factors such as inflammation, infection and malignancy, making it falsely elevated in an inflammatory state such as HF and thus does not correlate with iron availability [57]. We showed that, compared to bone marrow iron staining, the ESC definition of ID has a sensitivity of $82.4 \%$ and a specificity of $72 \%$ for detecting ID in patients with HF [54]. Serum iron $(\leq 13 \mu \mathrm{mol} / \mathrm{L})$ and TSAT $(\leq 19.8 \%)$ were significantly better cutoffs than the FAIR-HF definition, with areas under the curves (AUC) of 0.922 and 0.932, respectively. Adding ferritin to either definition did not result in a significant increase in the AUC, suggesting that ferritin does not contribute to more accurate identification of truly iron deficient $\mathrm{HF}$ patients, and as such, both serum iron $\leq 13 \mu \mathrm{mol} / \mathrm{L}$ and TSAT $\leq 19.8 \%$ are good indicators of ID as standalone. Prognostically, these two definitions are independently associated with a higher incidence of all-cause mortality, while isolated hypoferritinemia did not [54]. Several studies corroborated these findings [10,49,51,54,58-60]. More recently, it was found that persistent ID (defined as a serum iron $\leq 13 \mu \mathrm{mol} / \mathrm{L}$ ) was associated with poor prognosis, while its resolution was associated with improved outcomes. Similar trends were found when defining ID as TSAT $<20 \%$, but not when defined as per the FAIR-HF criteria [49]. Remarkably, Cleland et al. found that higher ferritin levels (and not lower levels) were significantly associated with a higher risk of all-cause or cardiovascular mortality, further questioning the correlation between ferritin and iron availability in patients with HF. Additionally, subgroup analysis of individual patient data meta-analysis $(n=839)$ pooled from four double-blind, randomised controlled trials (RCTs) showed that although intravenous ferric carboxymaltose (FCM) generally reduces recurrent cardiovascular hospitalisations and cardiovascular mortality, patients with TSAT $<20.1 \%$ benefit more from FCM iron than those with TSAT $>20.1 \%$ even if ferritin levels were low [61]. Similarly, in the IRON-CRT trial, it was found that HF patients with TSAT $<20 \%$ benefit more from FCM iron than if TSAT was $>20 \%$ in terms of cardiac contractility and left ventricular ejection fraction (LVEF) [62]. However, similar interaction was not found in the AFFIRM-AHF 
trial [27]. The aforementioned findings confirm the accuracy of TSAT $<20 \%$ and serum iron $\leq 13 \mu \mathrm{mol} / \mathrm{L}$ in identifying truly iron deficient HF patients while questioning the diagnostic and prognostic usage of ferritin in detecting ID in HF.

On the other hand, these two definitions of ID might have their own limitations, as serum iron is subjected to circadian variations [63], and TSAT might be falsely elevated in malnutrition and advanced stages of renal insufficiency [50,64-66]. Recent studies proposed serum soluble transferrin receptor (sTfR) as the most auspicious novel ID-related biomarker since circulating sTfR levels reflect the iron demand of the body in addition to the erythroid proliferation rate quantitatively [67]. In a similar approach to our bone marrow study, Sierpinski et al. found that ID defined as serum sTfR of $\geq 1.25 \mathrm{mg} / \mathrm{L}$ is more accurate in identifying ID when compared to bone marrow staining in clinically stable patients with HF [55]. Of note, adding sTfR to multivariable models for predicting 3-year all-cause mortality in patients with HF abolishes the prognostic value of serum ferritin and TSAT after adjusting for all other prognosticators. These findings suggest that elevated serum sTfR is a better surrogate for depleted intracellular iron. In line with these findings, Leszek et al. found that only serum sTfR significantly correlated to myocardial and mitochondrial iron status, but not ferritin, serum iron or TSAT [68], indicating that sTfR reflects tissue iron demands more accurately. Nevertheless, the lack of assay standardisation restricts its implementation in clinical routines [66].

To summarise, defining ID in HF using classical biochemical iron parameters appears to be not straightforward. Mounting evidence suggests that ferritin should not be taken into consideration when diagnosing ID in patients with HF but may be used as a safety parameter to avoid the administration of iron to patients with potential iron overload; TSAT or serum iron alone are better indicators of systemic ID, while sTfR might outperform them all. Although the current ESC definition of ID performed thus far reasonably good in general, it is broad and unspecific in identifying those who are truly iron deficient; the high prevalence of ID in HF might have precluded the importance of choosing a more accurate definition to identify those who are truly iron deficient and need IV iron. Identifying truly iron-deficient patients is crucial as inaccurate diagnoses of ID [49] and unnecessary treatment with FCM might dilute the benefits of IV iron and lead to increased risks such as hypophosphatemia [69]. Furthermore, in light of existing evidence indicating different mechanisms leading to myocardial and systemic ID [70] (as discussed below) as well as poor accuracy of systemic biomarkers in detecting myocardial ID, which might be a major driver behind clinical improvements upon iron supplementation, future studies should evaluate other ID-related surrogates in order to identify HF patients that might benefit from iron supplementation on a systemic and cellular level.

\section{Causes of Iron Deficiency in Heart Failure}

Replenishing iron stores using IV iron addresses the consequence of ID, but not the cause. Accordingly, the underlying aetiology should be investigated, as also indicated in the guidelines [8]. However, from these guidelines, it is unclear which causes should be sought for and which examinations should be performed.

The underlying causes of ID are poorly characterised. Multiple mechanisms are likely to be operational. A variety of postulated mechanisms have gained great attention to explain the high prevalence of ID in HF beyond anaemia. Several factors were shown to be independently associated with ID in HF, including advanced age, kidney failure, female gender, malnutrition, chronic inflammation, reduced iron absorption, increased iron loss and heart failure severity $[15,16,26,51]$. Of note, many of the aforementioned risk factors are postulated based on observational studies and have not yet been confirmed as a cause in patients with HF and thus, remain hypothetical.

Since iron status is the resultant of inflow and outflow, the causes of iron deficiency in HF can be classified into three categories: (1) reduced iron intake, (2) reduced iron absorption and (3) increased iron loss. In addition, specific causes of myocardial iron deficiency are discussed in the following sections. 


\subsection{Reduced Iron Intake and Low Iron Bioavailability}

In a large international cohort of 2357 patients with worsening HF, decreased estimated protein intake was used as a surrogate to estimate dietary iron intake. It was found that patients with lower estimated protein intake have a higher prevalence of ID (particularly absolute ID [71]), indicating poor nutritional status as a potential cause of ID in HF [51]. Studies show that approximately 35\% to $78 \%$ of HF patients suffer from malnutrition, which has also been independently associated with adverse outcomes [72-75]. The aetiology of malnutrition is complex and thought to be multifactorial where fatigue, dyspnoea, swallowing disturbances, nausea, anxiety, food monotony, reduced appetite and early satiety could play a role [76-78]. The advice to reduce dietary salt intake (albeit controversial $[79,80])$ could compromise the nutritional status of individual patients with HF [81,82]. Dietary intake of iron in HF patients assessed using a 4-day food diary is lower than the recommended intake in $46 \%$ of patients, with significantly lower intake in patients with NYHA class III-IV as compared to class II [83]. This suggests that malnutrition and subsequently lower iron intake is more severe as HF progresses. Other studies have also found inadequate iron intake in patients with HF, especially among women above 50 years $[84,85]$.

Iron absorption is closely tied to iron bioavailability, which is defined as the extent to which iron is absorbed from the ingested diet. Iron bioavailability is dependent on the form of iron consumed, haeme or non-haeme iron, which have different mechanisms of absorption [86]. Haeme iron, which is found in haemoglobin and myoglobin of animal food sources, is readily absorbed and contributes to $20-30 \%$ of the total absorbed iron [87]. Unlike haeme iron, intestinal absorption of non-haeme (derived from plants and ironfortified foods) is less readily absorbed and is dependent on the balance between absorption inhibitors and enhancing factors [86]. Ultimately, diets low in iron bioavailability, even if they consist of sufficient absolute amounts of iron, may lead to ID [88].

With the exception of calcium, which inhibits both forms of dietary iron, phytates and polyphenols (found in tea, coffee or chocolate) inhibit the absorption of non-haeme iron [86]. Vitamin $C$ and consumption of meat enhance absorption of non-haeme iron even in a plantbased phytate-rich diet [89]. Diet has been implicated as a risk factor for developing ID in HF. Multiple studies showed a higher prevalence of ID in Indians compared to other Southeast Asian and European populations [17,20,90-92], which potentially can be explained by dietary habits since vegetarianism and drinking tea is very common among the Indian population [93]. Besides containing mainly non-haeme iron, a plant-based diet is full of phytates and polyphenols, which are known potent inhibitors of non-haeme iron absorption, making vegetarians more prone to develop ID $[87,94,95]$. In a study of $226 \mathrm{HFrEF}$ patients from the Himachal Pradesh heart failure registry, it was found that HF patients that consume a vegetarian diet were 2.5 times more likely to have ID (odds ratio 2.5 (95\% confidence interval 1.4-4.6)) [96]. Therefore, poor diet and dietary habits seem one of the risk factors predisposing to ID in HF, and accordingly, recommending adequate nutritional intake might be crucial non-pharmacological advice for tackling ID in HF.

An alternate explanation of the inter-ethnic differences in ID prevalence could be the genetic makeup $[39,97]$. Individuals with mutations in the TMPRSS6 gene have higher hepcidin levels, preventing normal absorption of dietary iron and leading to iron-refractory IDA [39]. A meta-analysis of genome-wide association studies has shown that common variants in TMPRSS6 (especially the rs855791 SNP) were associated with lower $\mathrm{Hb}$ and ferritin but higher serum transferrin receptor and transferrin concentration, indicating susceptibility to ID. The minor allele frequency (MAF) of rs855791 varies across ethnic groups significantly, with the highest MAF being in Asian populations ( 0.55 in Asians vs. 0.42 in Caucasians, $p \leq 0.0001$ ) [98]. Other variants were also found to have ethnic differences [97]. These findings, together with the dietary habits, could predispose some populations more to ID. No study has yet investigated the relationship between the genetic makeup of HF patients in relation to ID.

Increasing Iron Intake: Is It Effective? 
Increasing iron intake orally in HF patients using Forceval (mix of micronutrients including $12 \mathrm{mg}$ of iron) for 12 months did not significantly increase serum ferritin or serum iron [94]. Furthermore, in the IRONOUT-HF study, it was found that taking oral iron polysaccharide tablets (150 mg twice daily) for 16 weeks did not improve functional capacity and quality of life in patients with HFrEF in spite of the minimal improvement in iron stores [95]. It is worth noting that the cumulative amount of oral iron received within the study period exceeds the recommended dosage intravenously to correct ID by more than 15 times [8,95]. Knowing that the main source of iron used by the body is endogenously obtained as a result of scavenging iron from senescent erythrocytes by macrophages [67], these results may implicate mechanisms other than insufficient dietary iron intake alone as a cause of ID in HF.

However, oral iron preparations differ in their tolerability, bioavailability and efficacy in correcting ID as they differ in their routes of absorption $[99,100]$. A recent small $(n=50)$ non-randomised open-label study showed that 3-month therapy using another formulation of oral iron (Sucrosomial iron) in iron-deficient HFrEF patients was significantly associated with improved iron indices, exercise capacity and quality of life [101]. Whether oral Sucrosomial iron (SI) can be used as a stand-alone or adjuvant therapy to IV iron supplementation is currently unknown. Two ongoing randomised controlled trials in HFpEF (PREFER-HF, NCT03833336) and HFrEF (IVOFER-HF, EudraCT 2017-005053-37) patients comparing FCM with SI iron will shed more light on the efficacy of SI.

\subsection{Reduced Iron Absorption}

In healthy individuals, iron absorption is determined by the form of iron consumed, iron absorption enhancers and/or inhibitors and iron status [45]. The physiological response to ID in otherwise healthy individuals is increased absorption of dietary iron [39]. Although HF patients are usually malnourished and the iron intake is suboptimal $[73,84,86]$, the cause of ID in these patients is probably not solely due to decreased intake. Reduced iron absorption is thought to be an important factor in causing ID in HF as it can explain why IV iron works in replenishing iron stores in iron-deficient HF while particular oral iron preparations do not [102]. IV iron bypasses regulatory mechanisms that are thought to reduce iron absorption in HF, overcoming the absorptive inflammatory blockade of intestinal iron absorption [103]. Several factors are thought to reduce iron absorption, leading to ID in HF.

\subsubsection{Impaired Intestinal Function}

ID is associated with right ventricular dysfunction [104], peripheral oedema and orthopnoea in HF [10,51], possibly implicating congestion in the pathogenesis of ID in HF [105]. HF patients have an altered intestinal morphology, permeability and absorption [106]. HF patients with venous congestion have reduced blood to the intestine, causing intestinal hypoperfusion and consequently nonocclusive bowel ischemia, increased mucosal permeability, bowel edema, cachexia and altered composition of mucosal bacteria [106-110]. Collectively, all of this might culminate in the malabsorption of micronutrients, including iron [111].

A study showed that in rats with IDA, morphological and functional compensatory mechanisms are important adaptive mechanisms to increase intestinal absorption of iron [112,113]. These mechanisms include increased cell proliferation, mucosal thickness, epithelial surface area, villus length and width. Given the altered intestinal morphology and function in HF, these adaptive mechanisms might not be operational to correct ID physiologically [114].

In addition to impaired intestinal morphological adaptations in patients with $\mathrm{HF}$, studies in animals showed that adaptive transcriptional mechanisms to counteract ID are defective in HF models. Unlike IDA rats without HF, in Dahl salt-sensitive HF rats, it was found that intestinal expression of important genes for intestinal iron absorption such as duodenal cytochrome b (Dcyt-b), divalent metal transporter 1 (DMT-1) and ferroprotein 
was not upregulated in spite of reduced hepcidin expression [114]. Remarkably, the expression of intestinal hypoxia-inducible transcription -2 (HIF-2 $\alpha$ ) did not increase in IDA-HF rats but increased in IDA rats without HF [114]. Upregulation in intestinal HIF-2 $\alpha$ is an essential adaptive mechanism to counteract ID by increasing iron absorption $[115,116]$. Taken together, this suggests an abnormal iron regulating system in HF, which impairs adaptive responses to correct ID physiologically. Interestingly, gut microbiome-derived metabolites are capable of modulating HIF-2 $\alpha$ signaling $[117,118]$. There is accumulating evidence implicating changes in the composition of the gut microbiome in the pathogenesis and perpetuation of HF [119]. Whether gut dysbiosis observed in patients with HF plays a role in ID pathogenesis is currently unknown.

A recent study, however, albeit small sample size $(n=30)$, showed that patients with $\mathrm{HF}$ and ID have higher oral iron absorption compared with age and sex-matched control subjects without ID [120]. Nonetheless, it is not clear whether this increase in absorption is due to HF or ID itself, as there was no comparison between subjects with ID and no HF to indicate whether HF might impair oral iron absorption. Larger studies are needed to ascertain the causal relationship between impaired absorption of iron and the development of ID in HF.

\subsubsection{Inflammation: Role of Interleukin-6 and Hepcidin}

HF is associated with an inflammatory state that results in increased production of inflammatory markers like interleukin-1(IL-1), interleukin-6(IL-6) and tumour necrosis factor alpha (TNF- $\alpha$ ). Inflammation is thought to play a role in causing ID in several chronic inflammatory diseases (such as cancer [121], CKD [122,123] and rheumatoid arthritis [124]), including HF, with hepcidin having a pivotal role herein [15,20,26,51,53,125-127]. IL-6 is the main inflammatory trigger of increased hepcidin expression [128]. Other cytokines can also induce hepatic hepcidin expression indirectly by upregulating IL- 6 such as TNF- $\alpha$, interferon alpha, activin B [129], or directly independent of IL-6 such as oncostatin M [130] and interleukin-22 [131]. Hepcidin internalises and degrades the only known iron exporter, ferroportin. Thereby, increased hepcidin levels lead to a decrease in iron absorption and mobilisation from the reticuloendothelial system, causing predominantly functional ID in HF [35,129].

Increased hepcidin levels have been directly linked to the pathogenesis of IDA associated with chronic inflammatory diseases such as cancer [121], CKD and autoimmune diseases [124,132]. In HF, however, data on associations between hepcidin, inflammation and ID are not consistent. In acutely decompensated HF patients admitted to the hospital, the prevalence of ID decreased after 30 days of discharge. This change in iron parameters was correlated, albeit weakly, with changes in inflammatory markers suggesting that inflammation may influence iron status [133]. In line with these findings, increased plasma IL-6 concentration was found to be associated with lower iron levels and higher hepcidin levels in an international cohort containing $2329 \mathrm{HF}$ patients [134]. In contrast, a study by Jankowska et al. found an inverse relationship between IL-6 and hepcidin [132]. However, in the BIOSTAT-CHF cohort, iron-deficient HF patients (defined as TSAT <20) were found to have lower hepcidin levels with higher levels of inflammatory markers (CRP) compared to patients without ID [51]. Subsequent analysis showed that higher hepcidin levels are significantly associated with a higher prevalence of FID but a lower prevalence of AID [71]. Many studies found no independent association between ID and inflammation when no distinction was made between FID and AID [16,132]. This may suggest differential involvement of inflammation in the pathophysiology of the two types of ID.

Reduced hepcidin levels in IDA have already been documented in animals [114] and human studies [70,132,135-138]. In patients with stable HF, an inverse relationship between hepcidin levels and HF severity was found, with levels of hepcidin in patients with NYHA class IV being significantly lower even when compared to healthy controls [132]. Whereas progression of HF is associated with heightened inflammatory response and 
increased prevalence of ID [15,16], hepcidin levels seem to decrease despite increased proinflammatory cytokines [132].

Increased inflammation, disordered iron balance, yet low hepcidin. What could explain these contradictory results? First, ID seems to have a more profound impact on hepcidin expression levels than inflammation as hepcidin expression is regulated by multiple pathways; depleted iron stores, hypoxia and ineffective erythropoiesis all decrease the expression of hepcidin, while inflammation induces its expression [139]. Although hepatic hepcidin expression is influenced by multiple factors, low plasma levels of hepcidin specifically reflect depleted iron stores $[48,50]$. The strength of each stimulus determines the expression of hepcidin rather than by an absolute hierarchy among signaling pathways [140]. Another possible explanation for the observed low hepcidin levels might be the chronological aspect of ID development. In other words, ID in HF may start being functional since high hepcidin levels were found in the early stages of HF [132], and if it lasts for a long time, absolute ID ensues. Future studies should investigate the sequence of changes in iron status in relation to the two types of ID in HF patients.

\subsection{3. b: Role of TNF- $\alpha$}

Lastly, other inflammatory markers may also lead to impaired iron metabolism in HF independently of hepcidin. In vitro models showed that treating immortalised human gastrointestinal epithelial cells with TNF- $\alpha$ led to reduced iron uptake significantly [141]. In mice, intraperitoneal injection with TNF- $\alpha$ caused ID by reducing intestinal iron absorption through decreasing the expression of DMT1 with no changes in hepatic hepcidin production [142]. However, Weber et al. showed in a relatively small cohort of HF patients $(n=60)$ that TNF- $\alpha$ was not significantly higher in HF patients with ID [135], which may suggest that TNF- $\alpha$ might not be the main driver behind ID in HF. However, convincing data on the relevance of this mechanism in leading to ID in patients with HF is lacking.

\subsubsection{Hypochlorhydria and Excess Alkalinisation}

Gastric acids play an important role in absorbing non-haeme iron [143]. A low pH is essential to convert non-bioavailable ferric $\left(\mathrm{Fe}^{3+}\right)$ iron to ferrous $\left(\mathrm{Fe}^{2+}\right)$ iron by ascorbic acid or Dcytb prior to absorption by DMT1 [144]. Impaired gastric acid production as a result of chronic use of gastric acid-inhibiting medication such as proton-pump inhibitors (PPIs) and histamine-2 receptor antagonists(H2Ras) reduces oral iron absorption greatly. PPIs and H2Ras increase $\mathrm{pH}$ and thereby reduce iron absorption [39]. These medications are routinely prescribed in clinical practice for treating peptic ulcers, dyspepsia, gastroesophageal reflux disease and / or prevention of gastrointestinal bleeding in patients using antiplatelets such as clopidogrel and/or anticoagulants such as warfarin. In the general population, chronic use of antacids was associated with an increased risk of developing ID [145,146]. Remarkably, using PPIs significantly inhibits the absorption of non-haeme iron even in patients with hereditary hemochromatosis where iron absorption is increased [147]. In a study comprised of $>22,000$ patients with HF, it was found that the use of PPIs is common $(29 \%)$, and the prevalence of anaemia among PPIs users was significantly higher [148]. However, only one study showed that iron-deficient HF patients were more likely to also use PPIs [51]. This association lost its significance after adjustments in multivariable logistic regression. PPIs are often co-prescribed with medications that cause GI bleeding, such as antiplatelets and/or anticoagulants [148], as well as NSAIDs (potential confounders) [51]. Hence, coexisting blood loss cannot be excluded as a cause of ID in HF, as explained below.

\subsection{Increased Iron Loss}

\section{Gastrointestinal Blood Loss}

Observational studies show that the prevalence of ID is substantially higher in older HF patients [15,16,51,149]. Most patients with HF are elderly [4]. ID in the elderly is almost always due to non-dietary factors [150,151], with colorectal cancer, colonic polyps and angiodysplasia being the most common causes [39]. Other potential causes of occult 
upper and lower GI bleeding include esophagitis, gastritis, peptic ulcer, or inflammatory bowel disease [152,153]. In developing countries, hookworm infection could also lead to iron loss [39]. In otherwise healthy individuals presenting with idiopathic IDA with no GI symptoms, more than half of the patients have GI abnormalities upon endoscopic investigations [149,154,155]. Another study, including 151 individuals with ID older than 70 years ( $83 \pm 6$ years), found a higher prevalence of GI lesions irrespective of anaemia (66\% in IDA vs. $65 \%$ in iron-deficient nonanemic patients) [156]. Of note, GI malignancies (gastric, oesophageal or colon cancer) were also found in $15 \%$ of them, independently of the presence of anaemia. Similar findings were also found in a larger Korean cohort [157]. In a study conducted by Martens et al. including $699 \mathrm{HF}$ patients who underwent a full endoscopic workup, it was found that GI malignancies in iron-deficient HF patients were present in around $10 \%$, with no statistically significant difference between those with IDA and ID without anaemia (9.3\% vs. $10.5 \%$, respectively; $p=0.551)$ [158].

Occult blood loss can be aggravated using medications. HF patients are more vulnerable to GI lesions compared to the general population as they have multiple risk factors for GI bleeding, including older age, multimorbidity and polypharmacy of medications that cause intestinal abnormalities. Antiplatelets (e.g., aspirin [159] and clopidogrel [160]) and/or anticoagulants (e.g., warfarin [161]) are known to increase GI bleeding by causing GI lesions, especially if used in combination [162-164]. Such complex dual and triple antithrombotic drug combinations increase the risk of GI bleeding substantially $[165,166]$. Remarkably, the presence of comorbidities amplifies the risk of GI bleeding when these agents are used, with HF being an independent risk factor [162,167-169]. This might suggest that HF patients have a vulnerable gastric mucosa, and using such medications to treat another comorbidity in HF makes them more susceptible to GI lesions. However, associations between ID in HF and the use of antiplatelet and/or anticoagulants are not consistent. Some studies found no association between ID and the use of these medications $[15,16,20]$, while only one study identified P2Y12 inhibitors as an independent predictor of ID [51].

Contrastingly, increasing evidence suggests that patients with HF have an increased risk of developing cancer $[163,164,170]$. Interestingly, iron has emerged as a potential cause for tumorigenesis, especially in colorectal cancer [171-174]. The contribution of ID to the incidence of cancer in HF patients is not yet elucidated and worth further investigation.

Altogether, elderly HF patients are at an increased risk of chronic GI bleeding, which is very likely to result in ID. In these patients, identification of ID should prompt further investigations as ID is most of the time indicative of underlying pathology, which might be potentially reversible.

\subsection{Systemic vs. Myocardial Iron Deficiency: Role of Neurohormonal Activation}

The aforementioned causes considered ID as extra-cardiac comorbidity that has an impact on patients with HF. However, mounting evidence indicates differences in mechanisms leading to cellular and systemic ID [175-177]. In HF, it is was found that myocardial ID (MID) is poorly related to systemic iron homoeostasis biomarkers [68,70], suggesting that MID may be caused by other mechanisms other than reduced systemic iron availability $[178,179]$. Petrak et al. revealed that hearts of volume overload-induced HF rats develop MID despite normal iron absorption and preserved systemic iron levels [180].

Neurohormonal activation, which is a hallmark feature of HF [181], is thought to be the main cause behind myocardial ID. Maeder et al. showed lower iron content in the myocardium of patients with HF correlating with a lower mRNA expression of transferrin receptor 1 (TFR1), which is the main pathway by which iron enters cardiomyocytes [182]. Experimentally, using cardiomyocytes from neonatal rats, they found that a reduction in TFR1 expression is linked to increased activation of the neuroendocrine system, particularly aldosterone and norepinephrine [182]. This suggests that myocardial ID is likely to be caused via neurohormonal activation by downregulating TFR1. Furthermore, HF patients with MID had a lower rate of using beta-blockers compared to non-MID HF patients [183]. Moreover, Haddad et al. highlighted the importance of iron-regulatory 
proteins (IRP-1 and IRP-2) to the heart in securing myocardial iron [178]. More recently, Tajes et al. demonstrated in mice with isoproterenol ( $\beta$-adrenoceptor agonist)-induced $\mathrm{HF}$ that neurohormonal activation leads to MID accompanied by mitochondrial dysfunction by reducing extracellular iron uptake and increasing intracellular iron release [33]. These findings were validated using embryonic rat heart-derived $\mathrm{H} 9 \mathrm{c} 2$ cells challenged with norepinephrine and/or angiotensin 2, which led to similar results [33]. This implies that neurohormonal activation worsens HF by decreasing myocardial iron, suggesting that ID may be more than merely a comorbidity. In line with these findings, cardiac iron content is two times lower in patients with end-stage HF compared to non-advanced HF (New York Heart Association class II or III) with reduced ejection fraction, which may suggest that MID develops or worsens during the course of HF [70].

These pre-clinical findings raise an intriguing hypothesis that systemic iron replacement may benefit patients with HF before the onset of systemic iron deficiency. The proactive approach of IV iron in patients with HF without apparent systemic IV remains to be investigated. In chronic kidney disease (CKD), the PIVOTAL trial demonstrated that in patients undergoing maintenance haemodialysis, high dose proactive IV iron sucrose (for those with ferritin $<700 \mathrm{ng} / \mathrm{mL}$ and TSAT $<40 \%$ ) showed both noninferiority and superiority for the primary endpoint (composite of death and major adverse cardiovascular events) compared to reactive low dose IV iron (for those with ferritin $<200 \mathrm{ng} / \mathrm{mL}$ or TSAT was $<20 \%$ ) with no significant difference in infection rate [184]. In addition, this proactive approach resulted in significantly fewer hospitalisations for HF, lower doses of erythropoiesis-stimulating agents used and a lower incidence of blood transfusion. Although this trial was not in HF patients, it does show benefits even in those seemingly iron-sufficient patients based on traditional definitions.

It should be emphasised that it is yet to be determined whether deregulation in intrinsic myocardial iron metabolism could lead to systemic ID in patients with HF. A crosssectional study composed of $742 \mathrm{HF}$ patients found an independent association between increased sympathetic activation and systemic ID as measured by the increased plasma norepinephrine levels [32]. More confirmatory studies are needed to answer whether MID caused by neurohormonal activation is an independent abnormality or a contributing factor towards systemic ID in patients with HF. An overview of the discussed mechanisms leading to ID in HF is summarised in Figure 2.

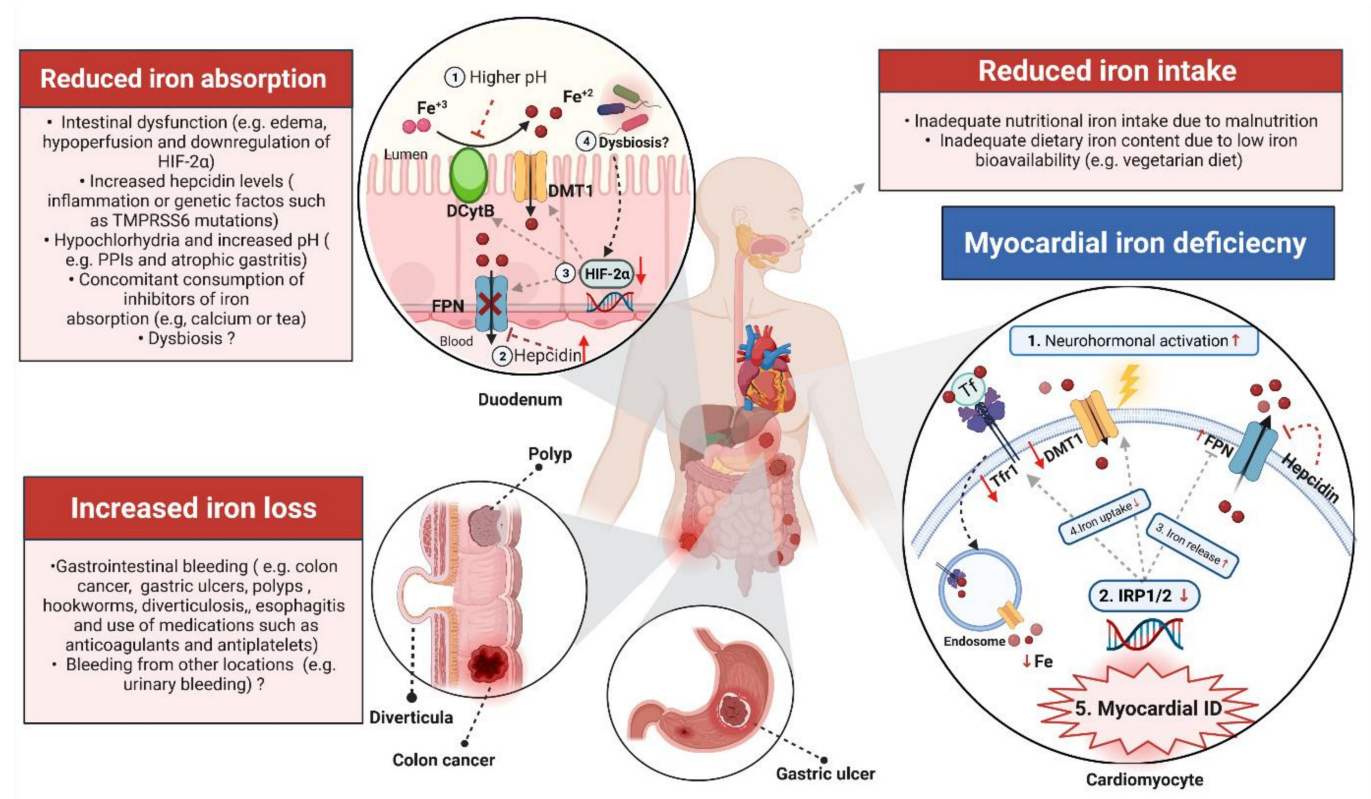

Figure 2. Summary of the current understanding of the mechanisms underlying iron deficiency in heart failure. This step is essential to enable iron uptake by the divalent metal transporter (DMT1).This 
reduction process is influenced by the $\mathrm{pH}$ of the luminal contents, and thus, any factors that influence the $\mathrm{pH}$, such as proton pump inhibitors, can impair non-haeme iron absorption. Within the enterocyte, iron can be stored in ferritin or exported into the bloodstream by the iron exporter ferroportin (FPN), which is controlled by hepcidin. Increased hepcidin levels internalise FPN, leading to sequestration of iron within the enterocytes and thus impairing absorption of iron to the blood. HIF-2 regulates transcription of DCytB, DMT1 and FPN iron transport machinery. Downregulation of HIF-2 can lead to a dysfunctional iron regulating system in HF. Gut microbial metabolites can decrease HIF-2 expression and thus may influence systemic iron homeostasis. The third mechanism that could also result in systemic ID is increased iron loss due to gastrointestinal pathology such as colon cancer. In the heart, neurohormonal activation leads to myocardial ID by downregulating iron-regulatory proteins (IRP1/2). Iron circulation in the heart is controlled by IRP1/2 and hepcidin. In turn, this defective downregulation of IRP1/2 as well as hepcidin leads to increased iron release (as a result of decreased hepcidin levels and thus higher FPN) and decreased iron uptake due to downregulation of transferrin receptor 1 and DMT1. (Created with BioRender.com, accessed on 24 November 2021).

\section{Deleterious Biological Consequences of Iron Deficiency}

The functional and clinical impairments as well as the benefits of correcting ID observed in non-anaemic iron-deficient HF patients point towards the important role of iron in nonhematopoietic tissues $[16,20,21,23,185,186]$. The underlying mechanisms between the worst symptomatic status and prognosis remain poorly characterised. Recent years sparked an avalanche of research seeking to explain the mechanisms by which ID contributes to these adverse effects. In order to understand the consequences of ID in HF patients beyond anaemia, consideration should be directed towards the roles of iron beyond mere erythropoiesis. In the following sections, the cellular and subcellular effects of ID are discussed. A summary of the deleterious effects of ID is shown in Figure 3.

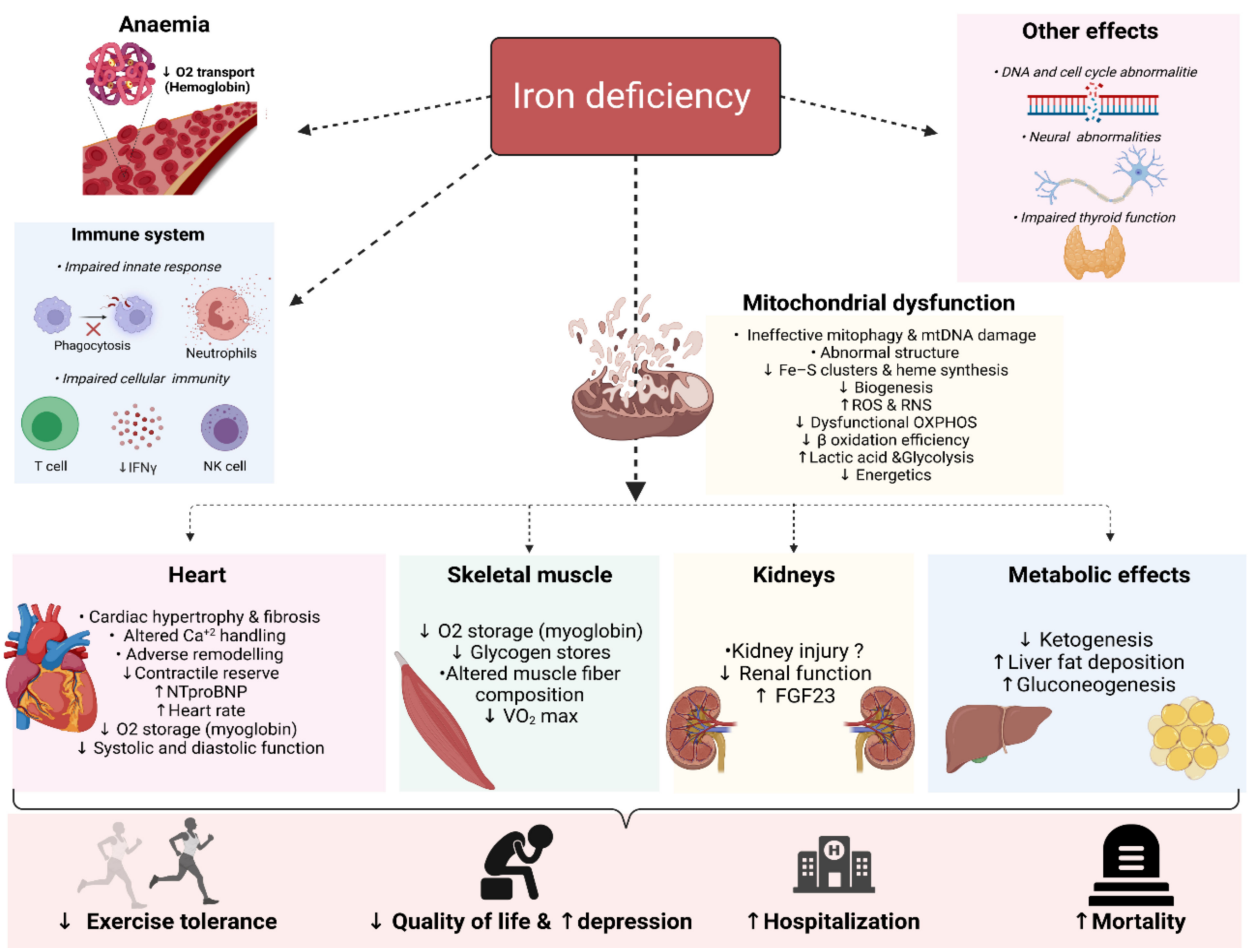

Figure 3. Overview of the biological consequences of iron deficiency. NTproBNP: N-terminal prob-type natriuretic peptide; OXPHOS: Oxidative phosphorylation; RNS: reactive nitrogen species; ROS: reactive oxygen species and FGF23: Fibroblast growth factor-23 (Created with BioRender.com, accessed on 24 November 2021). 


\subsection{Mitochondrial Function and Metabolic Effects}

Cells with high energy demand such as cardiomyocytes, hepatocytes, nephrons and skeletal myocytes are abundant with mitochondria. Mitochondria are the major intracellular sites of iron utilisation and accumulation as they are the sites where synthesis of haeme and iron-sulphur clusters takes place $[187,188]$. Beyond its biosynthetic role in haeme and iron-sulphur clusters, iron was also shown to be crucial for mitochondrial biogenesis as ID affects both iron-containing and non-iron-containing mitochondrial proteins, indicating a reciprocal relationship between adequate iron content and mitochondrial function [189].

Mitochondria are the primary combustion machinery in cells for burning fuel such as glucose, fatty acids and ketone bodies. The final step to producing adenosine triphosphate (ATP) from these nutrients is oxidative phosphorylation (OXPHOS), for which sufficient iron (in addition to other pathways) is vital. This fact highlights how crucial iron is for proper energetics in all cells.

Besides producing ATP, mitochondria are also involved in controlling cellular $\mathrm{Ca}^{2+}$ [190], generating reactive oxygen species, cellular death, synthesis of pyrimidine, amino acids and lipids [187]. Accordingly, deficiency in iron impairs mitochondrial function at many levels. ID has been linked to morphological changes in the mitochondria, such as an increase in size and a decrease in cristae [191], as well as functional changes such as reduced production of ATP [192], mitochondrial DNA damage [191], increased gluconeogenesis $[187,193]$, increased lactic acid production $[185,186,194]$, reduced mitochondrial biogenesis and impaired mitophagy $[179,189]$, increased mitochondrial cytochrome c release (and hence apoptosis) and reactive nitrogen species expression [195-200]. All of this culminates in mitochondrial damage. As such, ID may worsen HF by causing mitochondrial damage [201,202], and its correction augments mitochondrial function.

Oxidative Stress

Mitochondria are the primary source of production and scavenging of both reactive oxygen species (ROS) and reactive nitrogen species (RNS) [203,204]. Not only can iron excess lead to oxidative stress via Fenton-type reactions but ID was also shown to promote oxidative and nitrosative stress [204]. This is thought to be related to the reduced antioxidant activity (e.g., catalase enzyme) [205] and increased superoxide production as a result of mitochondrial dysfunction. In the heart samples of HF patients undergoing transplantation, myocardial ID is associated with reduced expression of key protective enzymes that scavenge ROS, such as catalase, glutathione peroxidase and superoxide dismutase 2 [183]. This may point towards ROS and/or RNS induction as an adverse consequence of ID, which is seen as one of the underlying mechanisms leading to myocardial remodeling and HF progression [206]. Toblli et al. showed that even without completely correcting anaemia, IV iron sucrose reversed the anaemia-induced cardiac remodeling, prevented cardiac fibrosis and improved cardiac function by mitigating oxidative/nitrosative stress and inflammation in the heart [207]. Furthermore, in another rat model of HF, intravenously administering iron resulted in higher tissue activity of the antioxidant superoxide dismutase [208]. A recent study found similar results in a mice model of myocardial infarction [209]. Several studies showed that ID participates in the induction of oxidative stress in many organs, including the liver and the kidneys [210,211]. All in all, ID makes cells more prone to oxidative/nitrosative damage, and its correction may ameliorate these adverse effects of ID.

\subsection{Heart}

Since the heart has the highest energy expenditure of all organs [212], intact performance of cardiomyocytes is inextricably linked to mitochondrial function, for which sufficient iron is vital. This makes cardiomyocytes especially susceptible to the adverse effects of ID. Depriving human cardiomyocytes of iron leads to impaired contractile function with reduced activity of respiratory complexes I, II and III [192]. Remarkably, these adverse effects of ID can be reversed by iron supplementation. Similarly, several animal studies showed that systemic ID, even without anaemia [213], is associated with structural 
changes in the heart, including cardiac hypertrophy, irregular sarcomere organisation, mitochondrial swelling, left ventricular(LV) dilation , LV hypertrophy, lung congestion and cardiac fibrosis [195,214-216]. In addition to structural remodelling, the hearts of mice with IDA exhibit a hypoxic phenotype and altered $\mathrm{Ca}^{2+}$ handling, with a metabolic shift towards lactic acid-producing glycolytic metabolism $[185,217]$. Furthermore, hearts of mice models with isolated myocardial ID without anaemia develop cardiomegaly, impaired contractile function, shifts towards anaerobic respiration, dysfunctional oxidative phosphorylation and impaired mitophagy despite normal systemic iron levels [178,179].

Failing human hearts are characterised by reduced total iron content $[69,193,218]$. Systemic ID and/or MID is associated with worse cardiac function, diminished contractile reserve [219], decreased mitochondrial enzymatic activities of both oxidative phosphorylation and anti-oxidative enzymes $[69,71,192,193]$. When taken together, these studies highlight the importance of normal iron content to the heart and that its deficiency could play a causal role in the pathogenesis of systolic and diastolic myocardial dysfunction as well as HF progression independently of systemic iron status.

Replenishing iron prevents abnormalities of $\mathrm{Ca}^{2+}$ handling, improves cardiac function and survival in rat models with HF [180]. In the Myocardial-IRON Trial, it was found that administering FCM intravenously in iron-deficient HF patients resulted in significant improvement in cardiac magnetic resonance sequences, indicating myocardial iron repletion [220]. This correction of ID was accompanied by improved right and left ventricular ejection fraction on the 7th day already [221]. Several other studies corroborate these positive echocardiographic effects of IV on the heart [216,222-225]. Remarkably, in HFrEF patients receiving cardiac resynchronisation therapy (CRT), the presence of ID is associated with diminished reverse remodelling and lesser likelihood of functional improvement after CRT implementation, suggesting that adequate myocardial iron content is a prerequisite to derive optimal benefits from CRT implantation with respect to reverse cardiac remodelling and improved cardiac function $[226,227]$. In line with these findings, the recent IRON-CRT trial showed that IV iron repletion reverses myocardial remodelling and boosts cardiac performance and contractility in patients receiving CRT, which were also accompanied by improvements in quality of life and exercise capacity [62]. These results demonstrate the incremental potential of IV iron in reverse cardiac remodelling in addition to guideline-directed therapies that induce reverse remodelling [228]. Whether IV iron can prevent myocardial remodelling inflicted by either ischaemic or non-ischaemic damage is not known. It is worth noting that although beneficial effects of IV iron on the failing heart are indubitable, some research indicates that mitochondrial iron chelation might also have beneficial effects for patients with HF $[177,218,229,230]$. Further work is needed to delineate the effects of IV iron both systemically and cellularly.

\subsection{Skeletal Muscles}

Exercise intolerance is a cardinal symptom of HF, with impaired oxidative metabolism, decreased blood perfusion to skeletal muscles and oxygen delivery implicated as potential causes [231]. Mitochondrial dysfunction inflicted by ID is not limited to the heart but extends to other organs, especially those with high energy demands such as skeletal muscles. Intuitively, decreased exercise capacity in ID is linked to defective $\mathrm{O} 2$ delivery due to anaemia. However, deficiency of iron impairs skeletal muscle function also by anaemia-independent pathways, which is oxidative metabolism and oxygen storage in myoglobin $[43,232]$. Several animal studies have shown that impaired exercise capacity is directly linked to ID due to diminished mitochondrial energy metabolism $[43,233]$. Even when hemoglobin levels were kept constant, iron-deficient animals showed a significantly lower exercise capacity accompanied by impaired oxidative metabolism, indicating a direct relationship between ID and impaired physical performance irrespective of anaemia [234,235]. A meta-analysis in athletes with isolated ID without anaemia showed that iron therapy improves systemic iron status and their aerobic capacity as evaluated using maximal oxygen consumption (VO2 max) [236]. Furthermore, in a knockout mice 
model of Tfr1 specifically to skeletal muscles, Barrientos et al. showed that isolated muscle ID had profound systemic metabolic effects besides impaired mitochondrial respiration in muscles, suggesting that muscle ID may have unrecognised effects on systemic energy homeostasis [237].

In patients with HF, results of the FAIR-HF, CONFIRM-HF and EFFECT-HF randomised controlled trials all indicate that iron repletion improved exercise capacity irrespective of attained hemoglobin levels [22-24]. Melenovsky et al. showed that iron-deficient HF patients exhibit more severe skeletal muscle myopathy than their iron-sufficient counterparts as assessed using Phosphorus-31 magnetic resonance spectroscopy ( $\left.{ }^{31} \mathrm{P} \mathrm{MRS}\right)$. By using the same approach, Charles-Edwards et al. showed that in iron-deficient HFrEF, IV iron isomaltoside significantly shortens phosphocreatine regeneration after exercise despite no change in haemoglobin levels, indicating enhanced skeletal muscle energetics already by 2 weeks [238]. Boosting skeletal muscle energetics seems to be an important mechanism by which correcting ID leads to beneficial outcomes in patients with HF.

\subsection{Kidneys}

The kidneys are another high-energy-demanding organ system with high mitochondrial content [239]. From an energetics perspective, reabsorption and secretion of solutes in the nephrons occur either passively or actively (e.g., $\mathrm{Na}^{+} / \mathrm{K}^{+}$-ATPase), with the latter requiring energy for proper functioning. As such, iron, due to its crucial role in the mitochondria, is important for kidney function [240]. Although ID is mostly seen as a consequence of renal diseases, several studies suggest that iron itself influences kidney function [241]. A recent Mendelian randomisation study investigated the causal effect of serum iron levels on kidney function in the general population. They found a $1.3 \%$ increase in estimated glomerular filtration rate per standard deviation increase in serum iron $(95 \%$ confidence interval $0.4-2.1 \% ; p=0.004)$, indicating a protective effect of higher iron levels on renal function [242]. In accordance with these findings, feeding rats an iron-deficient diet resulted in an increase in malondialdehyde (an indicator of increased lipid peroxidation) in the kidneys, suggesting that ID can also adversely affect the kidney through oxidative stress and mitochondrial dysfunction [210]. In children, ID was shown to be associated with tubular and glomerular damage accompanied by increased oxidative stress markers [243]. Whether ID has similar direct effects on the kidneys in patients with HF is unknown.

In patients with HF, Toblli et al. showed that IV iron in anaemic HF patients with CKD resulted in a significant improvement in renal function [244]. Similarly, in a subanalysis of the FAIR-HF trial, it was found that patients in the FCM group had an improved kidney function as evaluated by estimated Glomerular Filtration Rate (eGFR) [245]. This improvement in renal function was observed in all pre-specified subgroups, including HF patients with preserved renal function and those without anaemia. Remarkably, correcting ID might be associated with a reduction in fibroblast growth factor 23 (FGF23) [246,247], which was linked with worse clinical outcomes in both HF and renal disease [248]. This suggests that the benefits of IV iron on the kidneys may extend beyond its effects on the energetics of renal mitochondria. Future studies should look into the interaction between FGF23, iron status, heart and kidneys since FGF23 has been shown to decrease hepcidin expression [249], in addition to acting as a mediator between ID and its association with mortality in patients with HF [250].

Altogether, treating ID in HF patients may pose renoprotection properties. Data on the effects of ID on the kidneys are scarce. Further studies are therefore warranted. Moreover, given the established role of the kidneys in controlling systemic iron levels [241], it is yet to be ascertained whether impaired kidney function could increase urinary iron excretion and thereby cause ID in HF.

\subsection{The Immune System}

Beyond the cardiocentric perspective, iron homeostasis is also important for the immune system [43]. The relationship between iron and immunity is complex and bidirec- 
tional. As alluded to earlier, inflammation as an immune effector mechanism can lead to iron dysmetabolism, but iron dysmetabolism itself also causes adverse changes in immune function $[129,251]$.

ID can affect the immune system in multiple ways. ID negatively affects both the growth and effector mechanisms of the immune system. Deleterious effects of ID include reduced neutrophil activity (myeloperoxidase is iron-dependent), reducing functions of nuclear factor kappa and HIFs, nitric oxide (NO) formation, a defective proliferation of $\mathrm{T}$ cells (especially T helper 1 cells) [252] and impaired interleukin 2 production $[44,253,254]$. Howden et al. showed that activated CD4+ and CD8+ T-cells upregulate their transferrin receptor, suggesting that iron is important for T-cell activation [255]. In mice fed an irondeficient diet, altered T lymphocyte and natural killer (NK) cell activity was demonstrated, indicating impaired cellular mediated immunity [256,257].

Contrary to the overly simplistic view where ID is merely seen as a consequence of inflammation, studies showed that ID could perpetuate and amplify inflammation [127]. ID in mice induces and enhances inflammation when compared to mice with normal iron status [258]. A recent study in a rat post-myocardial infarction (MI) HF model showed that iron supplementation (FCM) reduces inflammation [208]. This dampening effect of iron is thought to be due to the important role of iron for immune cells to mount an effective immune response. In fact, more than 10 years ago, Toblli et al. showed that administration of iron sucrose intravenously in anemic HF patients led to a significant reduction in C-reactive protein [244]. Other studies corroborated this evidence [207]. When taken together, these results support the idea that ID itself can also have a direct adverse effect on the immune system and that its correction has advantages beyond merely stimulating erythropoiesis.

\subsection{The Brain}

Mental functions have biochemical bases, and hence dysregulation herein can lead to mental effects. A growing body of evidence suggests that iron is important for neurological functions as the brain is also a metabolically active organ, making it particularly susceptible to ID [259]. In addition to energy deficits of neural cells, ID can also impair synaptic plasticity, myelination and reduce the activity of multiple iron-dependent enzymes involved in dopamine and serotonin synthesis (monoamine oxidase, tyrosine hydroxylase and tryptophan hydroxylase) $[260,261]$. Several studies showed that brain ID leads to deficits in memory, learning, behaviour and emotional problems [262]. Low levels of serotonin due to ID may lead to a relapse of depression [263]. Psychological disorders such as depression are very common in HF patients [264]. Several studies reported a higher prevalence of depression in iron-deficient HF $[26,265,266]$. Whether systemic ID is associated with brain ID in HF patients is unknown. Moreover, the effects of IV iron in patients with HF on mental functioning have not been assessed yet.

\subsection{Thyroid Gland}

Accumulated evidence shows that thyroid dysfunction is linked with an increased risk for and worsening of HF $[8,267,268]$. ID impairs thyroid hormone metabolism by different mechanisms, including ineffective erythropoiesis, reduced thyroid peroxidase activity (haeme-containing enzyme) and increased hepatic inactivation of thyroid hormones $[269,270]$. Iron deficient HFpEF patients have a significantly higher prevalence of thyroid disease [265]. The therapeutic consequence of replenishing iron on thyroid function in HF has not been studied yet.

\section{Novel Therapeutic Options for Targeting Iron Metabolism}

Although iron replacement therapy remains to be the cornerstone of treating ID in HF, several experimental iron metabolism-targeting agents have been developed to treat IDA, many of which were evaluated in patients with CKD and cancer-related anaemia [271]. These treatment options increase iron absorption as well as the mobilisation of sequestered 
iron by either downregulating the synthesis and/or function of hepcidin or by stabilising HIFs as a result of Prolyl-4-hydroxylases (PHDs) inhibition [249].

Manipulation of the hepcidin-ferroportin axis seems an attractive target as the interplay between hepcidin and ferroportin is crucial for regulating iron status and aberrations in this pathway are centrally involved in the pathophysiology of FID [9]. Targeting hepcidin directly (e.g., LY2787106, Lexaptepid pegol or Anticalins), or indirectly by targeting inflammatory markers (e.g., IL-6), bone morphogenic protein 6 (BMP6) [LY3113593], was proposed as a treatment option for anaemia of inflammation as these agents were shown to increase intestinal iron absorption and mobilisation in phase 1 and/or 2 studies [249]. Moreover, blocking hepcidin's interaction with ferroportin using ferroportin antibodies (LY2928057) reduces ferroportin internalisation, thereby increasing mobilisation of sequestered iron from the reticuloendothelial system [272]. Manipulation of the hepcidin pathway in inflammatory conditions such as HF might be a compelling option to treat ID in HF besides targeting inflammation, especially in those with FID as they have clear inflammatory components accompanied by high hepcidin levels [71]. In a recent phase 1/2 clinical trial, Pergola et al. showed that administration of ziltivekimab, anti-IL-6 ligand antibody, led to a dose-dependent improvement in serum iron, TSAT, inflammatory markers and reduction in hepcidin in CKD patients on haemodialysis with hyporesponsiveness to erythropoiesis-stimulating agents [123]. Whether targeting inflammation by reducing IL-6 activity and thereby improving clinical outcomes and iron metabolism can also be a therapeutic option to patients with HF is unknown.

Another promising approach is the manipulation of the prolyl hydroxylase domain/hypoxia -inducible factor (PHD/HIF) pathway, which seems to be deranged in iron-deficient patients with HF $[12,185]$. Several HIFs stabilisers are being developed, some of which have entered/finished phase 3 of clinical trials, including Vadadustat, Daprodustat and Roxadustat [273]. Meta-analyses of several randomised controlled trials showed that PHD inhibitors increase the levels of hemoglobin, serum transferrin and increase intestinal iron absorption while reducing levels of hepcidin in anaemic CKD patients [273-275]. These effects seem to be independent of inflammation [273]. Such activation of HIF signalling can provide a physiologic approach towards improved iron metabolism and may complement and/or reduce the need for IV iron in iron-deficient patients with HF. Besides being orally administered, targeting this pathway may have other non-erythopoetic benefits, such as lowering cholesterol levels as well as blood pressure [276,277]. However, there are many concerns regarding its safety as stabilising HIFs might lead to unwanted effects such as promoting cancer development since HIFs modulate the expression of various proteins that are involved in energy metabolism, angiogenesis, cellular growth and differentiation [249]. Large, carefully designed, long-term clinical trials are required to clearly understand the effects of systemic activation of the HIF pathway on iron-deficient HF patients.

Lastly, it should be noted that these agents can mainly increase absorption or mobilisation of sequestered iron, making them potentially ineffective for patients who have AID. Whether targeting the PHD/HIF or hepcidin-ferroportin axes have additive or possibly even synergistic effects with IV iron to correct ID, improve iron mobilisation in a more physiological manner and prevent relapses of ID remains to be investigated.

\section{Current Knowledge Gaps}

In this review, we summarised the current understanding of ID pathophysiology as well as the molecular basis potentially explaining improvements observed in patients with HF after administration of IV iron. Despite more research being dedicated to understanding the role of ID in HF, countless aspects remain unresolved. Firstly, current mechanistic studies trying to explain the benefits of IV iron are cardiocentric in nature, while the role of iron is not limited to the heart. The studies observing the benefits of IV iron on other organs, e.g., the brain and kidneys, will facilitate understanding the pathophysiology of ID. Secondly, thus far, trials have considered patients with AID and FID as one homogeneous group, while observational studies show different associations between FID and AID [71,278]. 
Whether these two groups are actually heterogeneous and might respond differently to IV iron is still not completely understood. Thirdly, current evidence about IV iron in HF is mainly derived from trials using FCM, and minimal investigation has been performed on non-FCM iron supplements despite past and ongoing trials using other preparations (e.g., isomaltoside iron). There are limited data comparing the efficacy and safety of the different preparations of IV iron as well as regimens (e.g., when and how much should be administered) in patients with HF. Fourthly, given the role of the microbiome in the pathophysiology of HF [119], the intricate relationship between iron and gut microbiome [279] and that oral iron treatment alters the composition of the gut microbiome [280,281], it is unknown whether the composition of the gut microbiome might play a role in causing ID in $\mathrm{HF}$ and whether iron replacement might confer favorable effects on the gut bacterial diversity. Another avenue of research is the fact that current knowledge of ID in HF is mainly from studies including HF patients with reduced LVEF, while the role of ID in preserved and mildly reduced LVEF remains equivocal. Ongoing studies will shed more light on the role of IDunknown whether the composition of the gut microbiome might in the different shades of $\mathrm{HF}$, as well as whether correcting ID can improve the survival of $\mathrm{HF}$ patients. A summary of the current knowledge gaps discussed in this review is outlined in Figure 4.
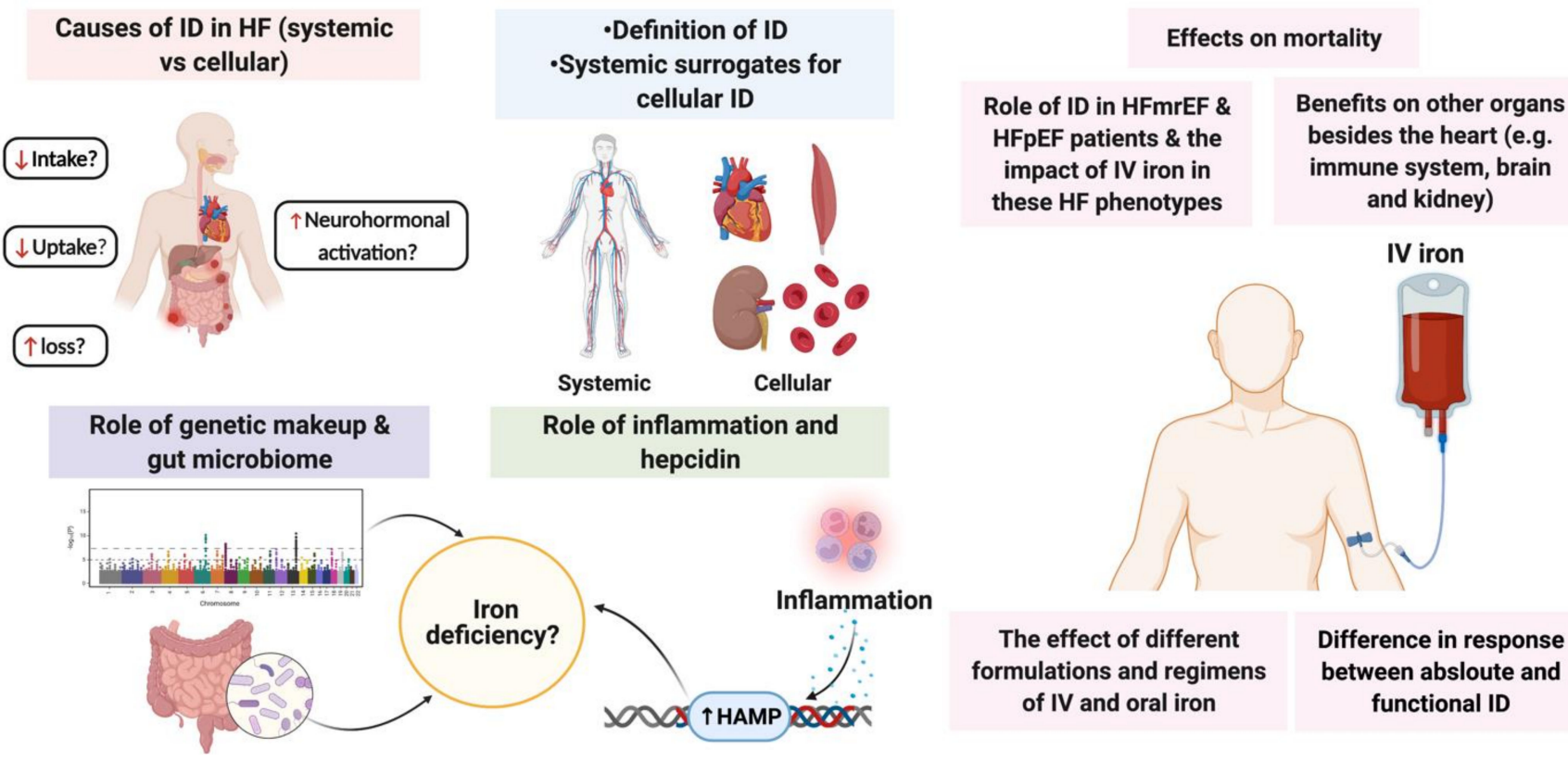

Figure 4. Summary of current knowledge gaps and future directions regarding iron deficiency in heart failure. ID: iron deficiency; HAMP: hepcidin; IV: intravenous; HF: heart failure; HFmrEF: heart failure with mildly reduced ejection fraction; HFpEF: heart failure with preserved ejection fraction. (Created with BioRender.com, accessed on 24 November 2021).

\section{Conclusions}

The consequences of ID per se reach far beyond those of anaemia. Energy deficit is one of the hallmarks of HF. Mounting evidence indicates that mitochondrial dysfunction is a prominent repercussion of ID, which further aggravates the existing deficit in energy in HF. Current standard-of-care pharmacological approaches to HF provide symptomatic and clinical benefits by reducing the workload on the heart instead of increasing its reserve. Targeting ID in HF can improve the care of HF patients as it addresses this shortcoming by augmenting mitochondrial function. This makes ID stand out as a therapeutic target in HF since it is relatively easy to diagnose and treat with potential anti-remodelling effects.

Despite recognition of ID as a novel therapeutic target in HF, its origin remains unclear, with recent studies distinguishing between mechanisms leading to systemic and MID as 
changes in these compartments seem to be not parallel. Neurohormonal activation links myocardial iron content with the pathophysiological cascade of HF. Whether MID may be part of the cause of systemic ID or a consequence is unknown. Several factors make HF patients particularly a vulnerable population to develop systemic ID. Longitudinal, mechanistic and intervention studies are needed to investigate the contribution of the different factors implicated in the pathophysiology of ID in HF.

Author Contributions: Conceptualization, R.I.S.A. and N.G.B. Methodology, R.I.S.A., M.F.H., N.G.B.; software, validation, formal analysis, investigation, resources, data curation, R.I.S.A. and N.G.B.; writing—original draft preparation, R.I.S.A. and N.G.B.; writing—review and editing, N.G.B., M.F.H., P.v.d.M. and D.J.v.V.; visualization, R.I.S.A.; supervision, P.v.d.M., N.G.B., M.F.H. and D.J.v.V.; project administration, funding acquisition. All authors have read and agreed to the published version of the manuscript.

Funding: This research received no external funding.

Institutional Review Board Statement: Not applicable.

Informed Consent Statement: Not applicable.

Conflicts of Interest: The UMCG, which employs several of the authors, has received institutional research support from Vifor Pharma, AstraZeneca, Ionis, Pfizer, Pharma Nord. N.G.B. received consulting fees from Vifor Pharma. P.v.d.M. received consulting fees from Vifor Pharma, Pharmacosmos and Novartis. The funders had no role in the design of the study; in the collection, analyses, or interpretation of data; in the writing of the manuscript, or in the decision to publish the results. All other authors have no relationships to disclose that could be construed as a conflict of interest.

\section{References}

1. Inamdar, A.; Inamdar, A. Heart Failure: Diagnosis, Management and Utilization. J. Clin. Med. 2016, 5, 62. [CrossRef] [PubMed]

2. Shah, K.S.; Xu, H.; Matsouaka, R.A.; Bhatt, D.L.; Heidenreich, P.A.; Hernandez, A.F.; Devore, A.D.; Yancy, C.W.; Fonarow, G.C. Heart Failure With Preserved, Borderline, and Reduced Ejection Fraction: 5-Year Outcomes. J. Am. Coll. Cardiol. 2017, 70, 2476-2486. [CrossRef] [PubMed]

3. Mamas, M.A.; Sperrin, M.; Watson, M.C.; Coutts, A.; Wilde, K.; Burton, C.; Kadam, U.T.; Kwok, C.S.; Clark, A.B.; Murchie, P.; et al. Do patients have worse outcomes in heart failure than in cancer? A primary care-based cohort study with 10-year follow-up in Scotland. Eur. J. Heart Fail. 2017, 19, 1095-1104. [CrossRef] [PubMed]

4. Conrad, N.; Judge, A.; Tran, J.; Mohseni, H.; Hedgecott, D.; Crespillo, A.P.; Allison, M.; Hemingway, H.; Cleland, J.G.; McMurray, J.J.V.; et al. Temporal trends and patterns in heart failure incidence: A population-based study of 4 million individuals. Lancet 2018, 391, 572-580. [CrossRef]

5. Braunstein, J.B.; Anderson, G.F.; Gerstenblith, G.; Weller, W.; Niefeld, M.; Herbert, R.; Wu, A.W. Noncardiac comorbidity increases preventable hospitalizations and mortality among medicare beneficiaries with chronic heart failure. J. Am. Coll. Cardiol. 2003, 42, 1226-1233. [CrossRef]

6. Van Deursen, V.M.; Urso, R.; Laroche, C.; Damman, K.; Dahlström, U.; Tavazzi, L.; Maggioni, A.P.; Voors, A.A. Co-morbidities in patients with heart failure: An analysis of the European Heart Failure Pilot Survey. Eur. J. Heart Fail. 2014, 16, 103-111. [CrossRef]

7. Drozd, M.; Relton, S.D.; Walker, A.M.N.; Slater, T.A.; Gierula, J.; Paton, M.F.; Lowry, J.; Straw, S.; Koshy, A.; McGinlay, M.; et al. Association of heart failure and its comorbidities with loss of life expectancy. Heart 2021, 107, 1417-1421. [CrossRef]

8. McDonagh, T.A.; Metra, M.; Adamo, M.; Gardner, R.S.; Baumbach, A.; Böhm, M.; Burri, H.; Butler, J.; Čelutkienè, J.; Chioncel, O.; et al. 2021 ESC Guidelines for the diagnosis and treatment of acute and chronic heart failure. Eur. Heart J. 2021, 42, 3599-3726. [CrossRef]

9. Anand, I.S.; Gupta, P. Anemia and Iron Deficiency in Heart Failure: Current Concepts and Emerging Therapies. Circulation 2018, 138, 80-98. [CrossRef]

10. Cleland, J.G.F.; Zhang, J.; Pellicori, P.; Dicken, B.; Dierckx, R.; Shoaib, A.; Wong, K.; Rigby, A.; Goode, K.; Clark, A.L. Prevalence and outcomes of anemia and hematinic deficiencies in patients with chronic heart failure. JAMA Cardiol. 2016, 1, 539-547. [CrossRef]

11. Grote Beverborg, N.; van Veldhuisen, D.J.; van der Meer, P. Anemia in Heart Failure: Still Relevant? JACC Hear. Fail. 2018, 6, 201-208. [CrossRef]

12. Alnuwaysir, R.I.S.; Grote Beverborg, N.; Hoes, M.F.; Markousis-Mavrogenis, G.; Gomez, K.A.; Wal, H.H.; Cleland, J.G.F.; Dickstein, K.; Lang, C.C.; Ng, L.L.; et al. Additional Burden of Iron Deficiency in Heart Failure Patients beyond the Cardio-Renal-Anaemia Syndrome: Findings from the BIOSTAT-CHF Study. Eur. J. Heart Fail. 2021. [CrossRef] 
13. Tkaczyszyn, M.; Comín-Colet, J.; Voors, A.A.; Van Veldhuisen, D.J.; Enjuanes, C.; Moliner-Borja, P.; Rozentryt, P.; Poló Nski, L.; Banasiak, W.; Ponikowski, P.; et al. Iron deficiency and red cell indices in patients with heart failure. Eur. J. Heart Fail. 2018, 20, 114-122. [CrossRef]

14. Klip, I.T.; Jankowska, E.A.; Enjuanes, C.; Voors, A.A.; Banasiak, W.; Bruguera, J.; Rozentryt, P.; Polonski, L.; Van Veldhuisen, D.J.; Ponikowski, P.; et al. The additive burden of iron deficiency in the cardiorenal-anaemia axis: Scope of a problem and its consequences. Eur. J. Heart Fail. 2014, 16, 655-662. [CrossRef]

15. Jankowska, E.A.; Rozentryt, P.; Witkowska, A.; Nowak, J.; Hartmann, O.; Ponikowska, B.; Borodulin-Nadzieja, L.; Banasiak, W.; Polonski, L.; Filippatos, G.; et al. Iron deficiency: An ominous sign in patients with systolic chronic heart failure. Eur. Heart J. 2010, 31, 1872-1880. [CrossRef]

16. Klip, I.T.; Comin-Colet, J.; Voors, A.A.; Ponikowski, P.; Enjuanes, C.; Banasiak, W.; Lok, D.J.; Rosentryt, P.; Torrens, A.; Polonski, L.; et al. Iron deficiency in chronic heart failure: An international pooled analysis. Am. Heart J. 2013, 165. [CrossRef]

17. Yeo, T.J.; Yeo, P.S.D.; Ching-Chiew Wong, R.; Ong, H.Y.; Leong, K.T.G.; Jaufeerally, F.; Sim, D.; Santhanakrishnan, R.; Lynn Lim, S.; Chan, M.M.; et al. Iron deficiency in a multi-ethnic Asian population with and without heart failure: Prevalence, clinical correlates, functional significance and prognosis. Eur. J. Heart Fail. 2014, 16, 1125-1132. [CrossRef]

18. Cohen-Solal, A.; Damy, T.; Terbah, M.; Kerebel, S.; Baguet, J.P.; Hanon, O.; Zannad, F.; Laperche, T.; Leclercq, C.; Concas, V.; et al. High prevalence of iron deficiency in patients with acute decompensated heart failure. Eur. J. Heart Fail. 2014, 16, 984-991. [CrossRef]

19. Ebner, N.; Jankowska, E.A.; Ponikowski, P.; Lainscak, M.; Elsner, S.; Sliziuk, V.; Steinbeck, L.; Kube, J.; Bekfani, T.; Scherbakov, N.; et al. The impact of iron deficiency and anaemia on exercise capacity and outcomes in patients with chronic heart failure. Results from the Studies Investigating Co-morbidities Aggravating Heart Failure. Int. J. Cardiol. 2016, 205, 6-12. [CrossRef]

20. Okonko, D.O.; Mandal, A.K.J.; Missouris, C.G.; Poole-Wilson, P.A. Disordered iron homeostasis in chronic heart failure: Prevalence, predictors, and relation to anemia, exercise capacity, and survival. J. Am. Coll. Cardiol. 2011, 58, 1241-1251. [CrossRef]

21. Jankowska, E.A.; Rozentryt, P.; Witkowska, A.; Nowak, J.; Hartmann, O.; Ponikowska, B.; Borodulin-Nadzieja, L.; Von Haehling, S.; Doehner, W.; Banasiak, W.; et al. Iron deficiency predicts impaired exercise capacity in patients with systolic chronic heart failure. J. Card. Fail. 2011, 17, 899-906. [CrossRef]

22. Anker, S.D.; Comin Colet, J.; Filippatos, G.; Willenheimer, R.; Dickstein, K.; Drexler, H.; Lüscher, T.F.; Bart, B.; Banasiak, W.; Niegowska, J.; et al. Ferric Carboxymaltose in Patients with Heart Failure and Iron Deficiency. N. Engl. J. Med. 2009, 361, 2436-2448. [CrossRef]

23. Van Veldhuisen, D.J.; Ponikowski, P.; Van Der Meer, P.; Metra, M.; Böhm, M.; Doletsky, A.; Voors, A.A.; MacDougall, I.C.; Anker, S.D.; Roubert, B.; et al. Effect of Ferric Carboxymaltose on Exercise Capacity in Patients with Chronic Heart Failure and Iron Deficiency. Circulation 2017, 136, 1374-1383. [CrossRef]

24. Ponikowski, P.; Van Veldhuisen, D.J.; Comin-Colet, J.; Ertl, G.; Komajda, M.; Mareev, V.; McDonagh, T.; Parkhomenko, A.; Tavazzi, L.; Levesque, V.; et al. Beneficial effects of long-term intravenous iron therapy with ferric carboxymaltose in patients with symptomatic heart failure and iron deficiency. Eur. Heart J. 2015, 36, 657-668. [CrossRef]

25. Jankowska, E.A.; Kirwan, B.-A.; Kosiborod, M.; Butler, J.; Anker, S.D.; McDonagh, T.; Dorobantu, M.; Drozdz, J.; Filippatos, G.; Keren, A.; et al. The effect of intravenous ferric carboxymaltose on health-related quality of life in iron-deficient patients with acute heart failure: The results of the AFFIRM-AHF study. Eur. Heart J. 2021, 42, 3011-3020. [CrossRef]

26. Jankowska, E.A.; Von Haehling, S.; Anker, S.D.; MacDougall, I.C.; Ponikowski, P. Iron deficiency and heart failure: Diagnostic dilemmas and therapeutic perspectives. Eur. Heart J. 2013, 34, 816-829. [CrossRef]

27. Ponikowski, P.; Kirwan, B.-A.; Anker, S.D.; McDonagh, T.; Dorobantu, M.; Drozdz, J.; Fabien, V.; Filippatos, G.; Göhring, U.M.; Keren, A.; et al. Ferric carboxymaltose for iron deficiency at discharge after acute heart failure: A multicentre, double-blind, randomised, controlled trial. Lancet 2020, 396, 1895-1904. [CrossRef]

28. Graham, F.J.; Pellicori, P.; Ford, I.; Petrie, M.C.; Kalra, P.R.; Cleland, J.G.F. Intravenous iron for heart failure with evidence of iron deficiency: A meta-analysis of randomised trials. Clin. Res. Cardiol. 2021, 110, 1299-1307. [CrossRef]

29. von Haehling, S.; Ebner, N.; Evertz, R.; Ponikowski, P.; Anker, S.D. Iron Deficiency in Heart Failure: An Overview. JACC Heart Fail. 2019, 7, 36-46. [CrossRef]

30. Pezel, T.; Audureau, E.; Mansourati, J.; Baudry, G.; Ben Driss, A.; Durup, F.; Fertin, M.; Godreuil, C.; Jeanneteau, J.; Kloeckner, M.; et al. Diagnosis and Treatment of Iron Deficiency in Heart Failure: OFICSel study by the French Heart Failure Working Group. ESC Heart Fail. 2021, 8, 1509-1521. [CrossRef]

31. Becher, P.M.; Schrage, B.; Benson, L.; Fudim, M.; Corovic Cabrera, C.; Dahlström, U.; Rosano, G.M.C.; Jankowska, E.A.; Anker S.D.; Lund, L.H.; et al. Phenotyping heart failure patients for iron deficiency and use of intravenous iron therapy: Data from the Swedish Heart Failure Registry. Eur. J. Heart Fail. 2021, 23, 1844-1854. [CrossRef] [PubMed]

32. Moliner, P.; Enjuanes, C.; Tajes, M.; Cainzos-Achirica, M.; Lupón, J.; Garay, A.; Jimenez-Marrero, S.; Yun, S.; Farré, N.; Cladellas, M.; et al. Association Between Norepinephrine Levels and Abnormal Iron Status in Patients With Chronic Heart Failure: Is Iron Deficiency More Than a Comorbidity? J. Am. Heart Assoc. 2019, 8, e010887. [CrossRef] [PubMed]

33. Tajes, M.; Díez-López, C.; Enjuanes, C.; Moliner, P.; Ferreiro, J.L.; Garay, A.; Jiménez-Marrero, S.; Yun, S.; Sosa, S.G.; Alcoberro, L.; et al. Neurohormonal activation induces intracellular iron deficiency and mitochondrial dysfunction in cardiac cells. Cell Biosci. 2021, 11, 89. [CrossRef] [PubMed] 
34. Silvestre, O.M.; Gonçalves, A.; Nadruz Jr, W.; Claggett, B.; Couper, D.; Eckfeldt, J.H.; Pankow, J.S.; Anker, S.D.; Solomon, S.D. Ferritin levels and risk of heart failure-the Atherosclerosis Risk in Communities Study. Eur. J. Heart Fail. 2017, 19, 340-347. [CrossRef]

35. Muckenthaler, M.U.; Rivella, S.; Hentze, M.W.; Galy, B. A Red Carpet for Iron Metabolism. Cell 2017, 168, 344-361. [CrossRef]

36. Andrews, N.C.; Schmidt, P.J. Iron homeostasis. Annu. Rev. Physiol. 2007, 69, 69-85. [CrossRef]

37. Cairo, G.; Bernuzzi, F.; Recalcati, S. A precious metal: Iron, an essential nutrient for all cells. Genes Nutr. 2006, 1, 25-39. [CrossRef]

38. Ponka, P.; Schulman, H.M.; Woodworth, R.C.; Richter, G.W. Iron Transport and Storage; CRC Press: Boca Raton, FL, USA, 2000.

39. Pasricha, S.R.; Tye-Din, J.; Muckenthaler, M.U.; Swinkels, D.W. Iron deficiency. Lancet 2021, 397, 233-248. [CrossRef]

40. Partin, A.C.; Ngo, T.D.; Herrell, E.; Jeong, B.C.; Hon, G.; Nam, Y. Heme enables proper positioning of Drosha and DGCR8 on primary microRNAs. Nat. Commun. 2017, 8, 1737. [CrossRef]

41. Zhang, C. Essential functions of iron-requiring proteins in DNA replication, repair and cell cycle control. Protein Cell 2014, 5 , 750-760. [CrossRef]

42. Ponikowski, P.; Kirwan, B.A.; Anker, S.D.; Dorobantu, M.; Drozdz, J.; Fabien, V.; Filippatos, G.; Haboubi, T.; Keren, A.; Khintibidze, I.; et al. Rationale and design of the AFFIRM-AHF trial: A randomised, double-blind, placebo-controlled trial comparing the effect of intravenous ferric carboxymaltose on hospitalisations and mortality in iron-deficient patients admitted for acute heart failure. Eur. J. Heart Fail. 2019, 21, 1651-1658. [CrossRef]

43. Beard, J.L. Iron biology in immune function, muscle metabolism and neuronal functioning. J. Nutr. 2001, 131, 568S-580S. [CrossRef]

44. Zohora, F.; Bidad, K.; Pourpak, Z.; Moin, M. Biological and Immunological Aspects of Iron Deficiency Anemia in Cancer Development: A Narrative Review. Nutr. Cancer 2018, 70, 546-556. [CrossRef]

45. Hentze, M.W.; Muckenthaler, M.U.; Galy, B.; Camaschella, C. Two to Tango: Regulation of Mammalian Iron Metabolism. Cell 2010, 142, 24-38. [CrossRef]

46. Silva, B.; Faustino, P. An overview of molecular basis of iron metabolism regulation and the associated pathologies. Biochim. Biophys. Acta-Mol. Basis Dis. 2015, 1852, 1347-1359. [CrossRef]

47. Ganz, T. Systemic iron homeostasis. Physiol. Rev. 2013, 93, 1721-1741. [CrossRef]

48. Lawen, A.; Lane, D.J.R. Mammalian iron homeostasis in health and disease: Uptake, storage, transport, and molecular mechanisms of action. Antioxidants Redox Signal. 2013, 18, 2473-2507. [CrossRef]

49. Graham, F.J.; Masini, G.; Pellicori, P.; Cleland, J.G.F.; Greenlaw, N.; Friday, J.; Kazmi, S.; Clark, A.L. Natural history and prognostic significance of iron deficiency and anaemia in ambulatory patients with chronic heart failure. Eur. J. Heart Fail. 2021. [CrossRef]

50. Jankowska, E.A.; Kasztura, M.; Sokolski, M.; Bronisz, M.; Nawrocka, S.; Oleśkowska-Florek, W.; Zymliński, R.; Biegus, J.; Siwołowski, P.; Banasiak, W.; et al. Iron deficiency defined as depleted iron stores accompanied by unmet cellular iron requirements identifies patients at the highest risk of death after an episode of acute heart failure. Eur. Heart J. 2014, 35, 2468-2476. [CrossRef]

51. Van der Wal, H.H.; Grote Beverborg, N.; Dickstein, K.; Anker, S.D.; Lang, C.C.; Ng, L.L.; van Veldhuisen, D.J.; Voors, A.A.; van der Meer, P. Iron deficiency in worsening heart failure is associated with reduced estimated protein intake, fluid retention, inflammation, and antiplatelet use. Eur. Heart J. 2019, 40, 3616-3625. [CrossRef]

52. Martens, P.; Grote Beverborg, N.; van der Meer, P. Iron deficiency in heart failure-Time to redefine. Eur. J. Prev. Cardiol. 2020, zwaa119. [CrossRef]

53. Ueda, T.; Kawakami, R.; Nogi, K.; Nogi, M.; Ishihara, S.; Nakada, Y.; Nakano, T.; Hashimoto, Y.; Nakagawa, H.; Nishida, T.; et al. Serum iron: A new predictor of adverse outcomes independently from serum hemoglobin levels in patients with acute decompensated heart failure. Sci. Rep. 2021, 11, 2395. [CrossRef]

54. Beverborg, N.G.; Klip, I.T.; Meijers, W.C.; Voors, A.A.; Vegter, E.L.; Van Der Wal, H.H.; Swinkels, D.W.; Van Pelt, J.; Mulder, A.B.; Bulstra, S.K.; et al. Definition of iron deficiency based on the gold standard of bone marrow iron staining in heart failure patients. Circ. Heart Fail. 2018, 11, e004519. [CrossRef]

55. Sierpinski, R.; Josiak, K.; Suchocki, T.; Wojtas-Polc, K.; Mazur, G.; Butrym, A.; Rozentryt, P.; Meer, P.; Comin-Colet, J.; Haehling, S.; et al. High soluble transferrin receptor in patients with heart failure: A measure of iron deficiency and a strong predictor of mortality. Eur. J. Heart Fail. 2021, 23, 919-932. [CrossRef]

56. Mei, Z.; Cogswell, M.E.; Parvanta, I.; Lynch, S.; Beard, J.L.; Stoltzfus, R.J.; Grummer-Strawn, L.M. Hemoglobin and ferritin are currently the most efficient indicators of population response to iron interventions: An analysis of nine randomized controlled trials. J. Nutr. 2005, 135, 1974-1980. [CrossRef] [PubMed]

57. Dignass, A.; Farrag, K.; Stein, J. Limitations of Serum Ferritin in Diagnosing Iron Deficiency in Inflammatory Conditions. Int. J. Chronic Dis. 2018, 2018, 9394060. [CrossRef] [PubMed]

58. Palau, P.; Llàcer, P.; Domínguez, E.; Tormo, J.P.; Zakarne, R.; Mollar, A.; Martínez, A.; Miñana, G.; Santas, E.; Almenar, L.; et al. Iron deficiency and short-term adverse events in patients with decompensated heart failure. Clin. Res. Cardiol. 2021, 110, 1292-1298. [CrossRef] [PubMed]

59. Gentil, J.R.d.S.; Fabricio, C.G.; Tanaka, D.M.; Suen, V.M.M.; Volpe, G.J.; Marchini, J.S.; Simões, M.V. Should we use ferritin in the diagnostic criteria of iron deficiency in heart failure patients? Clin. Nutr. ESPEN 2020, 39, 119-123. [CrossRef] [PubMed] 
60. Moliner, P.; Jankowska, E.A.; van Veldhuisen, D.J.; Farre, N.; Rozentryt, P.; Enjuanes, C.; Polonski, L.; Meroño, O.; Voors, A.A.; Ponikowski, P.; et al. Clinical correlates and prognostic impact of impaired iron storage versus impaired iron transport in an international cohort of 1821 patients with chronic heart failure. Int. J. Cardiol. 2017, 243, 360-366. [CrossRef]

61. Anker, S.D.; Kirwan, B.-A.; van Veldhuisen, D.J.; Filippatos, G.; Comin-Colet, J.; Ruschitzka, F.; Lüscher, T.F.; Arutyunov, G.P.; Motro, M.; Mori, C.; et al. Effects of ferric carboxymaltose on hospitalisations and mortality rates in iron-deficient heart failure patients: An individual patient data meta-analysis. Eur. J. Heart Fail. 2018, 20, 125-133. [CrossRef]

62. Martens, P.; Dupont, M.; Dauw, J.; Nijst, P.; Herbots, L.; Dendale, P.; Vandervoort, P.; Bruckers, L.; Tang, W.H.W.; Mullens, W. The effect of intravenous ferric carboxymaltose on cardiac reverse remodelling following cardiac resynchronization therapy-the IRON-CRT trial. Eur. Heart J. 2021, ehab411. [CrossRef]

63. Cao, G.Y.; Li, Y.; Jin, P.F.; Hu, X. Circadian rhythm in serum iron levels. Biol. Trace Elem. Res. 2012, 147, 63-66. [CrossRef]

64. Tomasz, G.; Ewa, W.; Jolanta, M. Biomarkers of iron metabolism in chronic kidney disease. Int. Urol. Nephrol. 2021, 53, 935-944. [CrossRef]

65. Yu, P.H.; Lin, M.Y.; Chiu, Y.W.; Lee, J.J.; Hwang, S.J.; Hung, C.C.; Chen, H.C. Low serum iron is associated with anemia in CKD stage 1-4 patients with normal transferrin saturations. Sci. Rep. 2021, 11, 8343. [CrossRef]

66. Pfeiffer, C.M.; Looker, A.C. Laboratory methodologies for indicators of iron status: Strengths, limitations, and analytical challenges. Am. J. Clin. Nutr. 2017, 106, 1606S-1614S. [CrossRef]

67. Manckoundia, P.; Konaté, A.; Hacquin, A.; Nuss, V.; Mihai, A.M.; Vovelle, J.; Dipanda, M.; Putot, S.; Barben, J.; Putot, A. Iron in the general population and specificities in older adults: Metabolism, causes and consequences of decrease or overload, and biological assessment. Clin. Interv. Aging 2020, 15, 1927-1938. [CrossRef]

68. Leszek, P.; Sochanowicz, B.; Szperl, M.; Kolsut, P.; Brzóska, K.; Piotrowski, W.; Rywik, T.M.; Danko, B.; Polkowska-Motrenko, H.; Rózański, J.M.; et al. Myocardial iron homeostasis in advanced chronic heart failure patients. Int. J. Cardiol. 2012, 159, 47-52. [CrossRef]

69. Wolf, M.; Rubin, J.; Achebe, M.; Econs, M.J.; Peacock, M.; Imel, E.A.; Thomsen, L.L.; Carpenter, T.O.; Weber, T.; Brandenburg, V.; et al. Effects of Iron Isomaltoside vs Ferric Carboxymaltose on Hypophosphatemia in Iron-Deficiency Anemia: Two Randomized Clinical Trials. JAMA 2020, 323, 432-443. [CrossRef]

70. Hirsch, V.G.; Tongers, J.; Bode, J.; Berliner, D.; Widder, J.D.; Escher, F.; Mutsenko, V.; Chung, B.; Rostami, F.; Guba-Quint, A.; et al Cardiac iron concentration in relation to systemic iron status and disease severity in non-ischaemic heart failure with reduced ejection fraction. Eur. J. Heart Fail. 2020, 22, 2038-2046. [CrossRef]

71. Grote Beverborg, N.; Van Der Wal, H.H.; Klip, I.T.; Anker, S.D.; Cleland, J.; Dickstein, K.; Van Veldhuisen, D.J.; Voors, A.A.; Van Der Meer, P. Differences in Clinical Profile and Outcomes of Low Iron Storage vs. Defective Iron Utilization in Patients with Heart Failure: Results from the DEFINE-HF and BIOSTAT-CHF Studies. JAMA Cardiol. 2019, 4, 696-701. [CrossRef]

72. Billingsley, H.E.; Hummel, S.L.; Carbone, S. The role of diet and nutrition in heart failure: A state-of-the-art narrative review. Prog. Cardiovasc. Dis. 2020, 63, 538-551. [CrossRef]

73. Kaluzna-Oleksy, M.; Sawczak, F.; Kukfisz, A.; Szczechla, M.; Krysztofiak, H.; Wleklik, M.; Przytarska, K.; Migaj, J.; Dudek, M.; Straburzyńska-Migaj, E.; et al. Appetite and Nutritional Status as Potential Management Targets in Patients with Heart Failure with Reduced Ejection Fraction-The Relationship between Echocardiographic and Biochemical Parameters and Appetite. J. Pers. Med. 2021, 11, 639. [CrossRef]

74. Belayachi, J.; Katir, I.; Bennis, R.N.; Madani, N.; Abouqal, R. Nutritional Status in Patients with Acute heart failure: A systematic review and meta-analysis with trial sequential analysis. medRxiv 2021. [CrossRef]

75. Ishikawa, Y.; Sattler, E.L.P. Nutrition as Treatment Modality in Heart Failure. Curr. Atheroscler. Rep. 2021, 23, 13. [CrossRef]

76. Abu-Sawwa, R.; Dunbar, S.B.; Quyyumi, A.A.; Sattler, E.L.P. Nutrition intervention in heart failure: Should consumption of the DASH eating pattern be recommended to improve outcomes? Heart Fail. Rev. 2019, 24, 565. [CrossRef]

77. Lennie, T.A.; Moser, D.K.; Heo, S.; Chung, M.L.; Zambroski, C.H. Factors influencing food intake in patients with heart failure: A comparison with healthy elders. J. Cardiovasc. Nurs. 2006, 21, 123-129. [CrossRef]

78. Fernández-Pombo, A.; Rodríguez-Carnero, G.; Castro, A.I.; Cantón-Blanco, A.; Seoane, L.M.; Casanueva, F.F.; Crujeiras, A.B.; Martínez-Olmos, M.A. Relevance of nutritional assessment and treatment to counteract cardiac cachexia and sarcopenia in chronic heart failure. Clin. Nutr. 2021, 40, 5141-5155. [CrossRef]

79. O'Donnell, M.; Mente, A.; Alderman, M.H.; Brady, A.J.B.; Diaz, R.; Gupta, R.; López-Jaramillo, P.; Luft, F.C.; Lüscher, T.F.; Mancia, G.; et al. Salt and cardiovascular disease: Insufficient evidence to recommend low sodium intake. Eur. Heart J. 2020, 41, 3363-3373. [CrossRef]

80. Khan, M.S.; Jones, D.W.; Butler, J. Salt, No Salt, or Less Salt for Patients With Heart Failure? Am. J. Med. 2020, 133, 32-38. [CrossRef]

81. Jefferson, K.; Ahmed, M.; Choleva, M.; Mak, S.; Allard, J.P.; Newton, G.E.; Arcand, J.A. Effect of a Sodium-Restricted Diet on Intake of Other Nutrients in Heart Failure: Implications for Research and Clinical Practice. J. Card. Fail. 2015, 21, 959-962. [CrossRef]

82. Colin-Ramirez, E.; McAlister, F.A.; Zheng, Y.; Sharma, S.; Ezekowitz, J.A. Changes in dietary intake and nutritional status associated with a significant reduction in sodium intake in patients with heart failure. A sub-analysis of the SODIUM-HF pilot study. Clin. Nutr. ESPEN 2016, 11, e26-e32. [CrossRef] [PubMed] 
83. Hughes, C.M.; Woodside, J.V.; McGartland, C.; Roberts, M.J.; Nicholls, D.P.; McKeown, P.P. Nutritional intake and oxidative stress in chronic heart failure. Nutr. Metab. Cardiovasc. Dis. 2012, 22, 376-382. [CrossRef] [PubMed]

84. Lourenço, B.H.; Vieira, L.P.; Macedo, A.; Nakasato, M.; De Fátima Nunes Marucci, M.; Bocchi, E.A. Nutritional status and adequacy of energy and nutrient intakes among heart failure patients. Arq. Bras. Cardiol. 2009, 93, 541-548. [CrossRef] [PubMed]

85. Grossniklaus, D.A.; O’Brien, M.C.; Clark, P.C.; Dunbar, S.B. Nutrient intake in heart failure patients. J. Cardiovasc. Nurs. 2008, 23, 357-363. [CrossRef]

86. Hurrell, R.; Egli, I. Iron bioavailability and dietary reference values. Am. J. Clin. Nutr. 2010, 91, 1461S-1467S. [CrossRef]

87. Carpenter, C.E.; Mahoney, A.W. Contributions of Heme and Nonheme Iron to Human Nutrition. Crit. Rev. Food Sci. Nutr. 1992, 31, 333-367. [CrossRef]

88. Hoppe, M.; Hulthén, L.; Hallberg, L. The importance of bioavailability of dietary iron in relation to the expected effect from iron fortification. Eur. J. Clin. Nutr. 2008, 62, 761-769. [CrossRef]

89. Bæch, S.B.; Hansen, M.; Bukhave, K.; Jensen, M.; Sørensen, S.S.; Kristensen, L.; Purslow, P.P.; Skibsted, L.H.; Sandström, B. Nonheme-iron absorption from a phytate-rich meal is increased by the addition of small amounts of pork meat. Am. J. Clin. Nutr. 2003, 77, 173-179. [CrossRef]

90. Sharma, S.K.; Agarwal, S.K.; Bhargava, K.; Sharma, M.; Chopra, K.; Arumugam, G. Prevalence and spectrum of iron deficiency in heart failure patients in south Rajasthan. Indian Heart J. 2016, 68, 493-497. [CrossRef]

91. Deora, S.; Sharma, J.B.; Sharma, S.; Chaudhary, N.; Kaushik, A.; Choudhary, R.; Charan, J.K.; Sharma, D.; Bohra, G.K.; Singh, K. Clinical characteristic, red blood cell indices, iron profile and prognosis of heart failure in females. Glob. Cardiol. Sci. Pract. 2021, 2021, e202113. [CrossRef]

92. Verma, S.; Dua, P.; Saini, A.; Chakraborty, P. Iron deficiency in chronic systolic heart failure(indic study). J. Pract. Cardiovasc. Sci. 2016, 2, 99. [CrossRef]

93. Ghoshal, U.C.; Singh, R. Frequency and risk factors of functional gastro-intestinal disorders in a rural Indian population. J. Gastroenterol. Hepatol. 2017, 32, 378-387. [CrossRef]

94. Negi, P.C.; Dev, M.; Paul, P.; Pal Singh, D.; Rathoure, S.; Kumar, R.; Dhiman, A.; Kandoria, A.; Ganju, N.; Sharma, R.; et al. Prevalence, risk factors, and significance of iron deficiency and anemia in nonischemic heart failure patients with reduced ejection fraction from a Himachal Pradesh heart failure registry. Indian Heart J. 2018, 70, S182-S188. [CrossRef]

95. Kang, W.; Barad, A.; Clark, A.G.; Wang, Y.; Lin, X.; Gu, Z.; O’Brien, K.O. Ethnic Differences in Iron Status. Adv. Nutr. 2021, 12, 1838-1853. [CrossRef]

96. Gichohi-Wainaina, W.N.; Towers, G.W.; Swinkels, D.W.; Zimmermann, M.B.; Feskens, E.J.; Melse-Boonstra, A. Inter-ethnic differences in genetic variants within the transmembrane protease, serine 6 (TMPRSS6) gene associated with iron status indicators: A systematic review with meta-analyses. Genes Nutr. 2015, 10, 442. [CrossRef]

97. McKeag, N.A.; McKinley, M.C.; Harbinson, M.T.; Noad, R.L.; Dixon, L.H.; McGinty, A.; Neville, C.E.; Woodside, J.V.; McKeown, P.P. The effect of multiple micronutrient supplementation on left ventricular ejection fraction in patients with chronic stable heart failure: A randomized, placebo-controlled trial. JACC Heart Fail. 2014, 2, 308-317. [CrossRef]

98. Lewis, G.D.; Malhotra, R.; Hernandez, A.F.; McNulty, S.E.; Smith, A.; Michael Felker, G.; Wilson Tang, W.H.; LaRue, S.J.; Redfield, M.M.; Semigran, M.J.; et al. Effect of oral iron repletion on exercise capacity in patients with heart failure with reduced ejection fraction and iron deficiency the IRONOUT HF randomized clinical trial. JAMA 2017, 317, 1958-1966. [CrossRef]

99. Gómez-Ramírez, S.; Brilli, E.; Tarantino, G.; Muñoz, M. Sucrosomial ${ }^{\circledR}$ iron: A new generation iron for improving oral supplementation. Pharmaceuticals 2018, 11, 97. [CrossRef]

100. Geisser, P.; Burckhardt, S. The pharmacokinetics and pharmacodynamics of iron preparations. Pharmaceutics 2011, 3, 12-33. [CrossRef]

101. Karavidas, A.; Troganis, E.; Lazaros, G.; Balta, D.; Karavidas, I.N.; Polyzogopoulou, E.; Parissis, J.; Farmakis, D. Oral sucrosomial iron improves exercise capacity and quality of life in heart failure with reduced ejection fraction and iron deficiency: A nonrandomized, open-label, proof-of-concept study. Eur. J. Heart Fail. 2021, 23, 593-597. [CrossRef]

102. Ghafourian, K.; Shapiro, J.S.; Goodman, L.; Ardehali, H. Iron and Heart Failure: Diagnosis, Therapies, and Future Directions. JACC Basic Transl. Sci. 2020, 5, 300-313. [CrossRef]

103. Richards, T.; Breymann, C.; Brookes, M.J.; Lindgren, S.; Macdougall, I.C.; McMahon, L.P.; Munro, M.G.; Nemeth, E.; Rosano, G.M.C.; Schiefke, I.; et al. Questions and answers on iron deficiency treatment selection and the use of intravenous iron in routine clinical practice. Ann. Med. 2021, 53, 274-285. [CrossRef]

104. Jian, J.; Yang, Q.; Dai, J.; Eckard, J.; Axelrod, D.; Smith, J.; Huang, X. Effects of iron deficiency and iron overload on angiogenesis and oxidative stress-a potential dual role for iron in breast cancer. Free Radic. Biol. Med. 2011, 50, 841-847. [CrossRef]

105. Suzuki, T.; Hanawa, H.; Jiao, S.; Ohno, Y.; Hayashi, Y.; Yoshida, K.; Kashimura, T.; Obata, H.; Minamino, T. Inappropriate expression of hepcidin by liver congestion contributes to anemia and relative iron deficiency. J. Card. Fail. 2014, 20, 268-277. [CrossRef]

106. Sandek, A.; Bauditz, J.; Swidsinski, A.; Buhner, S.; Weber-Eibel, J.; von Haehling, S.; Schroedl, W.; Karhausen, T.; Doehner, W.; Rauchhaus, M.; et al. Altered Intestinal Function in Patients With Chronic Heart Failure. J. Am. Coll. Cardiol. 2007, 50, 1561-1569. [CrossRef]

107. Sundaram, V.; Fang, J.C. Gastrointestinal and Liver Issues in Heart Failure. Circulation 2016, 133, 1696-1703. [CrossRef] 
108. Sandek, A.; Swidsinski, A.; Schroedl, W.; Watson, A.; Valentova, M.; Herrmann, R.; Scherbakov, N.; Cramer, L.; Rauchhaus, M.; Grosse-Herrenthey, A.; et al. Intestinal blood flow in patients with chronic heart failure: A link with bacterial growth, gastrointestinal symptoms, and cachexia. J. Am. Coll. Cardiol. 2014, 64, 1092-1102. [CrossRef]

109. Valentova, M.; Von Haehling, S.; Bauditz, J.; Doehner, W.; Ebner, N.; Bekfani, T.; Elsner, S.; Sliziuk, V.; Scherbakov, N.; Murín, J.; et al. Intestinal congestion and right ventricular dysfunction: A link with appetite loss, inflammation, and cachexia in chronic heart failure. Eur. Heart J. 2016, 37, 1684-1691. [CrossRef]

110. Raja, K.; Kochhar, R.; Sethy, P.K.; Dutta, U.; Bali, H.K.; Varma, J.S. An endoscopic study of upper-GI mucosal changes in patients with congestive heart failure. Gastrointest. Endosc. 2004, 60, 887-893. [CrossRef]

111. von Haehling, S.; Doehner, W.; Anker, S.D. Nutrition, metabolism, and the complex pathophysiology of cachexia in chronic heart failure. Cardiovasc. Res. 2007, 73, 298-309. [CrossRef]

112. Wayhs, M.L.C.; Patrício, F.S.R.; Amancio, O.M.S.; Pedroso, M.Z.; Fagundes Neto, U.; Morais, M.B. Morphological and functional alterations of the intestine of rats with iron-deficiency anemia. Braz. J. Med. Biol. Res. 2004, 37, 1631-1635. [CrossRef] [PubMed]

113. Smith, M.W.; Debnam, E.S.; Dashwood, M.R.; Srai, S.K.S. Structural and cellular adaptation of duodenal iron uptake in rats maintained on an iron-deficient diet. Pflug. Arch. Eur. J. Physiol. 2000, 439, 449-454. [CrossRef] [PubMed]

114. Naito, Y.; Tsujino, T.; Fujimori, Y.; Sawada, H.; Akahori, H.; Hirotani, S.; Ohyanagi, M.; Masuyama, T. Impaired expression of duodenal iron transporters in Dahl salt-sensitive heart failure rats. J. Hypertens. 2011, 29, 741-748. [CrossRef] [PubMed]

115. Mastrogiannaki, M.; Matak, P.; Keith, B.; Simon, M.C.; Vaulont, S.; Peyssonnaux, C. HIF-2 $\alpha$, but not HIF-1 $\alpha$, promotes iron absorption in mice. J. Clin. Invest. 2009, 119, 1159-1166. [CrossRef]

116. Shah, Y.M.; Matsubara, T.; Ito, S.; Yim, S.H.; Gonzalez, F.J. Intestinal Hypoxia-Inducible Transcription Factors Are Essential for Iron Absorption following Iron Deficiency. Cell Metab. 2009, 9, 152-164. [CrossRef]

117. Das, N.K.; Schwartz, A.J.; Barthel, G.; Inohara, N.; Liu, Q.; Sankar, A.; Hill, D.R.; Ma, X.; Lamberg, O.; Schnizlein, M.K.; et al. Microbial Metabolite Signaling Is Required for Systemic Iron Homeostasis. Cell Metab. 2020, 31, 115-130. [CrossRef]

118. Bielik, V.; Kolisek, M. Bioaccessibility and bioavailability of minerals in relation to a healthy gut microbiome. Int. J. Mol. Sci. 2021, 22, 6803. [CrossRef]

119. Branchereau, M.; Burcelin, R.; Heymes, C. The gut microbiome and heart failure: A better gut for a better heart. Rev. Endocr. Metab. Disord. 2019, 20, 407-414. [CrossRef]

120. Cabrera, C.C.; Ekström, M.; Linde, C.; Persson, H.; Hage, C.; Eriksson, M.J.; Wallén, H.; Persson, B.; Tornvall, P.; Lyngå, P. Increased iron absorption in patients with chronic heart failure and iron deficiency. J. Card. Fail. 2020, 26, 440-443. [CrossRef]

121. Shu, T.; Jing, C.; Lv, Z.; Xie, Y.; Xu, J.; Wu, J. Hepcidin in tumor-related iron deficiency anemia and tumor-related anemia of chronic disease: Pathogenic mechanisms and diagnosis. Eur. J. Haematol. 2015, 94, 67-73. [CrossRef]

122. Begum, S.; Latunde-Dada, G.O. Anemia of inflammation with an emphasis on chronic kidney disease. Nutrients 2019, 11, 2424. [CrossRef]

123. Pergola, P.E.; Devalaraja, M.; Fishbane, S.; Chonchol, M.; Mathur, V.S.; Smith, M.T.; Lo, L.; Herzog, K.; Kakkar, R.; Davidson, M.H. Ziltivekimab for treatment of anemia of inflammation in patients on hemodialysis: Results from a phase $1 / 2$ multicenter, randomized, double-blind, placebo-controlled trial. J. Am. Soc. Nephrol. 2021, 32, 211-222. [CrossRef]

124. Abdel-Khalek, M.A.; El-Barbary, A.M.; Essa, S.A.M.; Ghobashi, A.S. Serum hepcidin: A direct link between anemia of inflammation and coronary artery atherosclerosis in patients with rheumatoid arthritis. J. Rheumatol. 2011, 38, 2153-2159. [CrossRef]

125. Wang, C.Y.; Babitt, J.L. Hepcidin regulation in the anemia of inflammation. Curr. Opin. Hematol. 2016, 23, 189-197. [CrossRef]

126. Parikh, A.; Natarajan, S.; Lipsitz, S.R.; Katz, S.D. Iron deficiency in community-dwelling US adults with self-reported heart failure in the National Health and Nutrition Examination Survey III: Prevalence and associations with anemia and inflammation. Circ. Heart Fail. 2011, 4, 599-606. [CrossRef]

127. Ganz, T.; Nemeth, E. Iron homeostasis in host defence and inflammation. Nat. Rev. Immunol. 2015, 15, 500-510. [CrossRef]

128. Nemeth, E.; Valore, E.V.; Territo, M.; Schiller, G.; Lichtenstein, A.; Ganz, T. Hepcidin, a putative mediator of anemia of inflammation, is a type II acute-phase protein. Blood 2003, 101, 2461-2463. [CrossRef]

129. Mu, Q.; Chen, L.; Gao, X.; Shen, S.; Sheng, W.; Min, J.; Wang, F. The role of iron homeostasis in remodeling immune function and regulating inflammatory disease. Sci. Bull. 2021, 66, 1806-1816. [CrossRef]

130. Chung, B.; Verdier, F.; Matak, P.; Deschemin, J.; Mayeux, P.; Vaulont, S. Oncostatin M is a potent inducer of hepcidin, the iron regulatory hormone. FASEB J. 2010, 24, 2093-2103. [CrossRef]

131. Wallace, D.F.; Subramaniam, V.N. Analysis of IL-22 contribution to hepcidin induction and hypoferremia during the response to LPS in vivo. Int. Immunol. 2015, 27, 281-287. [CrossRef]

132. Jankowska, E.A.; Malyszko, J.; Ardehali, H.; Koc-Zorawska, E.; Banasiak, W.; Von Haehling, S.; MacDougall, I.C.; Weiss, G.; McMurray, J.J.V.; Anker, S.D.; et al. Iron status in patients with chronic heart failure. Eur. Heart J. 2013, 34, 827-834. [CrossRef] [PubMed]

133. Van Aelst, L.N.L.; Abraham, M.; Sadoune, M.; Lefebvre, T.; Manivet, P.; Logeart, D.; Launay, J.-M.; Karim, Z.; Puy, H.; Cohen-Solal, A. Iron status and inflammatory biomarkers in patients with acutely decompensated heart failure: Early in-hospital phase and 30-day follow-up. Eur. J. Heart Fail. 2017, 19, 1075-1076. [CrossRef] [PubMed]

134. Markousis-Mavrogenis, G.; Tromp, J.; Ouwerkerk, W.; Devalaraja, M.; Anker, S.D.; Cleland, J.G.; Dickstein, K.; Filippatos, G.S.; van der Harst, P.; Lang, C.C.; et al. The clinical significance of interleukin-6 in heart failure: Results from the BIOSTAT-CHF study. Eur. J. Heart Fail. 2019, 21, 965-973. [CrossRef] [PubMed] 
135. Weber, C.S.; Beck-Da-Silva, L.; Goldraich, L.A.; Biolo, A.; Clausell, N. Anemia in heart failure: Association of hepcidin levels to iron deficiency in stable outpatients. Acta Haematol. 2013, 129, 55-61. [CrossRef] [PubMed]

136. Matsumoto, M.; Tsujino, T.; Lee-Kawabata, M.; Naito, Y.; Akahori, H.; Sakoda, T.; Ohyanagi, M.; Tomosugi, N.; Masuyama, T. Iron regulatory hormone hepcidin decreases in chronic heart failure patients with anemia. Circ. J. 2010, 74, 301-306. [CrossRef] [PubMed]

137. Van Der Putten, K.; Jie, K.E.; Van Den Broek, D.; Kraaijenhagen, R.J.; Laarakkers, C.; Swinkels, D.W.; Braam, B.; Gaillard, C.A. Hepcidin-25 is a marker of the response rather than resistance to exogenous erythropoietin in chronic kidney disease/chronic heart failure patients. Eur. J. Heart Fail. 2010, 12, 943-950. [CrossRef]

138. Divakaran, V.; Mehta, S.; Yao, D.; Hassan, S.; Simpson, S.; Wiegerinck, E.; Swinkels, D.W.; Mann, D.L.; Afshar-Kharghan, V. Hepcidin in anemia of chronic heart failure. Am. J. Hematol. 2011, 86, 107-109. [CrossRef]

139. Nicolas, G.; Chauvet, C.; Viatte, L.; Danan, J.L.; Bigard, X.; Devaux, I.; Beaumont, C.; Kahn, A.; Vaulont, S. The gene encoding the iron regulatory peptide hepcidin is regulated by anemia, hypoxia, and inflammation. J. Clin. Invest. 2002, 110, 1037-1044. [CrossRef]

140. Huang, H.; Constante, M.; Layoun, A.; Santos, M.M. Contribution of STAT3 and SMAD4 pathways to the regulation of hepcidin by opposing stimuli. Blood 2009, 113, 3593-3599. [CrossRef]

141. Johnson, D.; Bayele, H.; Johnston, K.; Tennant, J.; Srai, S.K.; Sharp, P. Tumour necrosis factor alpha regulates iron transport and transporter expression in human intestinal epithelial cells. FEBS Lett. 2004, 573, 195-201. [CrossRef]

142. Laftah, A.H.; Sharma, N.; Brookes, M.J.; Mckie, A.T.; Simpson, R.J.; Iqbal, T.H.; Tselepis, C. Tumour necrosis factor $\alpha$ causes hypoferraemia and reduced intestinal iron absorption in mice. Biochem. J. 2006, 397, 61-67. [CrossRef]

143. Gulec, S.; Anderson, G.J.; Collins, J.F. Mechanistic and regulatory aspects of intestinal iron absorption. Am. J. Physiol.—Gastrointest. Liver Physiol. 2014, 307, G397. [CrossRef]

144. Sharp, P.; Srai, S.K. Molecular mechanisms involved in intestinal iron absorption. World J. Gastroenterol. 2007, 13, 4716-4724. [CrossRef]

145. Lam, J.R.; Schneider, J.L.; Quesenberry, C.P.; Corley, D.A. Proton Pump Inhibitor and Histamine-2 Receptor Antagonist Use and Iron Deficiency. Gastroenterology 2017, 152, 821-829. [CrossRef]

146. Tran-Duy, A.; Connell, N.J.; Vanmolkot, F.H.; Souverein, P.C.; de Wit, N.J.; Stehouwer, C.D.A.; Hoes, A.W.; de Vries, F.; de Boer, A. Use of proton pump inhibitors and risk of iron deficiency: A population-based case-control study. J. Intern. Med. 2019, 285, 205-214. [CrossRef]

147. Hutchinson, C.; Geissler, C.A.; Powell, J.J.; Bomford, A. Proton pump inhibitors suppress absorption of dietary non-haem iron in hereditary haemochromatosis. Gut 2007, 56, 1291-1295. [CrossRef]

148. Oudit, G.Y.; Bakal, J.A.; McAlister, F.A.; Ezekowitz, J.A. Use of oral proton pump inhibitors is not associated with harm in patients with chronic heart failure in an ambulatory setting. Eur. J. Heart Fail. 2011, 13, 1211-1215. [CrossRef]

149. Lopez-Contreras, M.J.; Zamora-Portero, S.; Lopez, M.A.; Marin, J.F.; Zamora, S.; Perez-Llamas, F. Dietary intake and iron status of institutionalized elderly people: Relationship with different factors. J. Nutr. Health Aging 2010, 14, 816-821. [CrossRef]

150. Wawer, A.A.; Jennings, A.; Fairweather-Tait, S.J. Iron status in the elderly: A review of recent evidence. Mech. Ageing Dev. 2018, 175, 55-73. [CrossRef]

151. Busti, F.; Campostrini, N.; Martinelli, N.; Girelli, D. Iron deficiency in the elderly population, revisited in the hepcidin era. Front. Pharmacol. 2014, 5, 83. [CrossRef]

152. Richter, J.M. Occult gastrointestinal bleeding. Gastroenterol. Clin. N. Am. 1994, 23, 53-66. [CrossRef]

153. Rockey, D.C.; Cello, J.P. Evaluation of the Gastrointestinal Tract in Patients with Iron-Deficiency Anemia. New Engl. J. Med. 1993, 329, 1691-1695. [CrossRef]

154. Wilcox, C.M.; Alexander, L.N.; Clark, W.S. Prospective evaluation of the gastrointestinal tract in patients with iron deficiency and no systemic or gastrointestinal symptoms or signs. Am. J. Med. 1997, 103, 405-409. [CrossRef]

155. Odhaib, S.A.; Mohammed, M.J.; Hammadi, S. Efficacy of Gastrointestinal Endoscopy in 398 Patients With Iron Deficiency Anemia Who Lack Gastrointestinal Symptoms: Basrah Experience. Cureus 2020, 12, e9206. [CrossRef]

156. Joosten, E.; Ghesquiere, B.; Linthoudt, H.; Krekelberghs, F.; Dejaeger, E.; Boonen, S.; Flamaing, J.; Pelemans, W.; Hiele, M.; Gevers, A.M. Upper and lower gastrointestinal evaluation of elderly inpatients who are iron deficient. Am. J. Med. 1999, 107, 24-29. [CrossRef]

157. Park, J.S.; Park, D.I.; Park, S.K.; Choi, J.S.; Kim, Y.H.; Chang, D.K.; Son, H.J.; Kim, J.E.; Kim, J.O.; Lee, S.H.; et al. Endoscopic evaluation of significant gastrointestinal lesions in patients with iron deficiency with and without anaemia: A Korean Association for the Study of Intestinal Disease Study. Intern. Med. J. 2009, 39, 441-446. [CrossRef]

158. Martens, P.; Minten, L.; Dupont, M.; Mullens, W. Prevalence of underlying gastrointestinal malignancies in iron-deficient heart failure. ESC Hear. Fail. 2019, 6, 37-44. [CrossRef]

159. Sostres, C.; Lanas, A. Gastrointestinal effects of aspirin. Nat. Rev. Gastroenterol. Hepatol. 2011, 8, 385-394. [CrossRef]

160. Lin, C.C.; Hu, H.Y.; Luo, J.C.; Peng, Y.L.; Hou, M.C.; Lin, H.C.; Lee, F.Y. Risk factors of gastrointestinal bleeding in clopidogrel users: A nationwide population-based study. Aliment. Pharmacol. Ther. 2013, 38, 1119-1128. [CrossRef]

161. Ruff, C.T.; Giugliano, R.P.; Braunwald, E.; Hoffman, E.B.; Deenadayalu, N.; Ezekowitz, M.D.; Camm, A.J.; Weitz, J.I.; Lewis, B.S.; Parkhomenko, A.; et al. Comparison of the efficacy and safety of new oral anticoagulants with warfarin in patients with atrial fibrillation: A meta-analysis of randomised trials. Lancet 2014, 383, 955-962. [CrossRef] 
162. Abraham, N.S.; Hartman, C.; Richardson, P.; Castillo, D.; Street, R.L.; Naik, A.D. Risk of Lower and upper gastrointestinal bleeding, transfusions, and hospitalizations with complex antithrombotic therapy in elderly patients. Circulation 2013, 128, 1869-1877. [CrossRef] [PubMed]

163. Abraham, N.S. Gastrointestinal bleeding in cardiac patients: Epidemiology and evolving clinical paradigms. Curr. Opin. Gastroenterol. 2014, 30, 609-614. [CrossRef] [PubMed]

164. Crooks, C.J.; West, J.; Card, T.R. Comorbidities affect risk of nonvariceal upper gastrointestinal bleeding. Gastroenterology 2013, 144, 1384. [CrossRef] [PubMed]

165. Weil, J.; Colin-Jones, D.G.; Langman, M.J.S.; Wainwright, P.; Lawson, D.H.; Rawlins, M.; Logan, R.F.A.; Brown, T.P.; Vessey, M.P.; Murphy, M. Peptic ulcer bleeding: Accessory risk factors and interactions with non- steroidal anti-inflammatory drugs. Gut 2000, 46, 27-31. [CrossRef]

166. Cosma, A.-S.; Bănescu, C.; Mocan, S.; Balla, B.; Negovan, A. Congestive Heart Failure and Upper Digestive Endoscopic Lesions. Acta Med. Marisiensis 2019, 65, 19-24. [CrossRef]

167. Negovan, A.; Iancu, M.; Moldovan, V.; Sàrkàny, K.; Bataga, S.; Mocan, S.; Tilea, I.; Banescu, C. The contribution of clinical and pathological predisposing factors to severe gastro-duodenal lesions in patients with long-term low-dose aspirin and proton pump inhibitor therapy. Eur. J. Intern. Med. 2017, 44, 62-66. [CrossRef]

168. de Boer, R.A.; Aboumsallem, J.P.; Bracun, V.; Leedy, D.; Cheng, R.; Patel, S.; Rayan, D.; Zaharova, S.; Rymer, J.; Kwan, J.M.; et al. A new classification of cardio-oncology syndromes. Cardio-Oncology 2021, 7, 24. [CrossRef]

169. Aboumsallem, J.P.; Moslehi, J.; de Boer, R.A. Reverse Cardio-Oncology: Cancer Development in Patients With Cardiovascular Disease. J. Am. Heart Assoc. 2020, 9, e013754. [CrossRef]

170. Hasin, T.; Gerber, Y.; Weston, S.A.; Jiang, R.; Killian, J.M.; Manemann, S.M.; Cerhan, J.R.; Roger, V.L. Heart Failure After Myocardial Infarction Is Associated With Increased Risk of Cancer. J. Am. Coll. Cardiol. 2016, 68, 265-271. [CrossRef]

171. Aksan, A.; Farrag, K.; Aksan, S.; Schroeder, O.; Stein, J. Flipside of the Coin: Iron Deficiency and Colorectal Cancer. Front. Immunol. 2021, 12, 635899. [CrossRef]

172. Phipps, O.; Brookes, M.J.; Al-Hassi, H.O. Iron deficiency, immunology, and colorectal cancer. Nutr. Rev. 2021, 79, 88-97. [CrossRef]

173. Pfeifhofer-Obermair, C.; Tymoszuk, P.; Petzer, V.; Weiss, G.; Nairz, M. Iron in the tumor microenvironment-connecting the dots. Front. Oncol. 2018, 8, 549. [CrossRef]

174. Jian, J.; Yang, Q.; Shao, Y.; Axelrod, D.; Smith, J.; Singh, B.; Krauter, S.; Chiriboga, L.; Yang, Z.; Li, J.; et al. A link between premenopausal iron deficiency and breast cancer malignancy. BMC Cancer 2013, 13, 307. [CrossRef]

175. Koleini, N.; Shapiro, J.S.; Geier, J.; Ardehali, H. Ironing out mechanisms of iron homeostasis and disorders of iron deficiency. J. Clin. Invest. 2021, 131, e148671. [CrossRef]

176. Paterek, A.; Mackiewicz, U.; Mączewski, M. Iron and the heart: A paradigm shift from systemic to cardiomyocyte abnormalities. J. Cell. Physiol. 2019, 234, 21613-21629. [CrossRef]

177. Lupu, M.; Tudor, D.V.; Filip, G.A. Influence of mitochondrial and systemic iron levels in heart failure pathology. Heart Fail. Rev. 2019, 24, 647-659. [CrossRef]

178. Haddad, S.; Wang, Y.; Galy, B.; Korf-Klingebiel, M.; Hirsch, V.; Baru, A.M.; Rostami, F.; Reboll, M.R.; Heineke, J.; Flögel, U.; et al. Iron-regulatory proteins secure iron availability in cardiomyocytes to prevent heart failure. Eur. Heart J. 2016, 38 , ehw333. [CrossRef]

179. Xu, W.; Barrientos, T.; Mao, L.; Rockman, H.A.; Sauve, A.A.; Andrews, N.C. Lethal Cardiomyopathy in Mice Lacking Transferrin Receptor in the Heart. Cell Rep. 2015, 13, 533-545. [CrossRef]

180. Petrak, J.; Havlenova, T.; Krijt, M.; Behounek, M.; Franekova, J.; Cervenka, L.; Pluhacek, T.; Vyoral, D.; Melenovsky, V. Myocardial iron homeostasis and hepcidin expression in a rat model of heart failure at different levels of dietary iron intake. Biochim. Biophys. Acta-Gen. Subj. 2019, 1863, 703-713. [CrossRef]

181. Hartupee, J.; Mann, D.L. Neurohormonal activation in heart failure with reduced ejection fraction. Nat. Rev. Cardiol. 2016, 14, 30-38. [CrossRef]

182. Maeder, M.T.; Khammy, O.; Dos Remedios, C.; Kaye, D.M. Myocardial and systemic iron depletion in heart failure: Implications for anemia accompanying heart failure. J. Am. Coll. Cardiol. 2011, 58, 474-480. [CrossRef]

183. Melenovsky, V.; Petrak, J.; Mracek, T.; Benes, J.; Borlaug, B.A.; Nuskova, H.; Pluhacek, T.; Spatenka, J.; Kovalcikova, J.; Drahota, Z.; et al. Myocardial iron content and mitochondrial function in human heart failure: A direct tissue analysis. Eur. J. Heart Fail. 2016, 19, 522-530. [CrossRef]

184. Macdougall, I.C.; White, C.; Anker, S.D.; Bhandari, S.; Farrington, K.; Kalra, P.A.; McMurray, J.J.V.; Murray, H.; Tomson, C.R.V.; Wheeler, D.C.; et al. Intravenous Iron in Patients Undergoing Maintenance Hemodialysis. N. Engl. J. Med. 2019, 380, 447-458. [CrossRef]

185. Paul, B.T.; Manz, D.H.; Torti, F.M.; Torti, S.V. Mitochondria and Iron: Current questions. Expert Rev. Hematol. 2017, 10, 65-79. [CrossRef]

186. Sheeran, F.L.; Pepe, S. Mitochondrial bioenergetics and dysfunction in failing heart. In Mitochondrial Dynamics in Cardiovascular Medicine; Advances in Experimental Medicine and Biology; Springer: New York, NY, USA, 2017; Volume 982, pp. 65-80.

187. Rensvold, J.W.; Ong, S.E.; Jeevananthan, A.; Carr, S.A.; Mootha, V.K.; Pagliarini, D.J. Complementary RNA and protein profiling identifies iron as a key regulator of mitochondrial biogenesis. Cell Rep. 2013, 3, 237-245. [CrossRef] 
188. Baughman, J.M.; Perocchi, F.; Girgis, H.S.; Plovanich, M.; Belcher-Timme, C.A.; Sancak, Y.; Bao, X.R.; Strittmatter, L.; Goldberger, O.; Bogorad, R.L.; et al. Integrative genomics identifies MCU as an essential component of the mitochondrial calcium uniporter. Nature 2011, 476, 341-345. [CrossRef]

189. Walter, P.B.; Knutson, M.D.; Paler-Martinez, A.; Lee, S.; Xu, Y.; Viteri, F.E.; Ames, B.N. Iron deficiency and iron excess damage mitochondria and mitochondrial DNA in rats. Proc. Natl. Acad. Sci. USA 2002, 99, 2264-2269. [CrossRef]

190. Hoes, M.F.; Grote Beverborg, N.; Kijlstra, J.D.; Kuipers, J.; Swinkels, D.W.; Giepmans, B.N.G.; Rodenburg, R.J.; van Veldhuisen, D.J.; de Boer, R.A.; van der Meer, P. Iron deficiency impairs contractility of human cardiomyocytes through decreased mitochondrial function. Eur. J. Heart Fail. 2018, 20, 910-919. [CrossRef]

191. Kitamura, N.; Yokoyama, Y.; Taoka, H.; Nagano, U.; Hosoda, S.; Taworntawat, T.; Nakamura, A.; Ogawa, Y.; Tsubota, K.; Watanabe, M. Iron supplementation regulates the progression of high fat diet induced obesity and hepatic steatosis via mitochondrial signaling pathways. Sci. Rep. 2021, 11, 10753. [CrossRef]

192. Finch, C.A.; Gollnick, P.D.; Hlastala, M.P.; Miller, L.R.; Dillmann, E.; Mackler, B. Lactic acidosis as a result of iron deficiency. J. Clin. Invest. 1979, 64, 129-137. [CrossRef]

193. Chung, Y.J.; Swietach, P.; Curtis, M.K.; Ball, V.; Robbins, P.A.; Lakhal-Littleton, S. Iron-Deficiency Anemia Results in Transcriptional and Metabolic Remodeling in the Heart Toward a Glycolytic Phenotype. Front. Cardiovasc. Med. 2021, 7, 361. [CrossRef] [PubMed]

194. Biegus, J.; Zymliński, R.; Sokolski, M.; Jankowska, E.A.; Banasiak, W.; Ponikowski, P. Elevated lactate in acute heart failure patients with intracellular iron deficiency as an identifier of poor outcome. Kardiol. Pol. 2019, 77, 347-354. [CrossRef] [PubMed]

195. Dong, F.; Zhang, X.; Culver, B.; Chew, H.G.; Kelley, R.O.; Ren, J. Dietary iron deficiency induces ventricular dilation, mitochondrial ultrastructural aberrations and cytochrome c release: Involvement of nitric oxide synthase and protein tyrosine nitration. Clin. Sci. 2005, 109, 277-286. [CrossRef] [PubMed]

196. Toblli, J.E.; Cao, G.; Rivas, C.; Kulaksiz, H. Heart and iron deficiency anaemia in rats with renal insufficiency: The role of hepcidin. Nephrology 2008, 13, 636-645. [CrossRef]

197. Dziegala, M.; Kasztura, M.; Kobak, K.; Bania, J.; Banasiak, W.; Ponikowski, P.; Jankowska, E.A. Influence of the availability of iron during hypoxia on the genes associated with apoptotic activity and local iron metabolism in rat $\mathrm{H} 9 \mathrm{C} 2$ cardiomyocytes and L6G8C5 skeletal myocytes. Mol. Med. Rep. 2016, 14, 3969-3977. [CrossRef]

198. Kasztura, M.; Dziegała, M.; Kobak, K.; Bania, J.; Mazur, G.; Banasiak, W.; Ponikowski, P.; Jankowska, E.A. Both iron excess and iron depletion impair viability of rat H9C2 cardiomyocytes and L6G8C5 myocytes. Kardiol. Pol. 2017, 75, 267-275. [CrossRef]

199. Dziegala, M.; Kobak, K.; Kasztura, M.; Bania, J.; Josiak, K.; Banasiak, W.; Ponikowski, P.; Jankowska, E. Iron Depletion Affects Genes Encoding Mitochondrial Electron Transport Chain and Genes of Non Oxidative Metabolism, Pyruvate Kinase and Lactate Dehydrogenase, in Primary Human Cardiac Myocytes Cultured upon Mechanical Stretch. Cells 2018, 7, 175. [CrossRef]

200. Kamei, A.; Watanabe, Y.; Ishijima, T.; Uehara, M.; Arai, S.; Kato, H.; Nakai, Y.; Abe, K. Dietary iron-deficient anemia induces a variety of metabolic changes and even apoptosis in rat liver: A DNA microarray study. Physiol. Genomics 2010, 42, 149-156. [CrossRef]

201. Narula, J.; Kolodgie, F.D.; Virmani, R. Apoptosis and cardiomyopathy. Curr. Opin. Cardiol. 2000, 15, 183-188. [CrossRef]

202. Brown, D.A.; Perry, J.B.; Allen, M.E.; Sabbah, H.N.; Stauffer, B.L.; Shaikh, S.R.; Cleland, J.G.F.; Colucci, W.S.; Butler, J.; Voors, A.A.; et al. Expert consensus document: Mitochondrial function as a therapeutic target in heart failure. Nat. Rev. Cardiol. 2017, 14, 238-250. [CrossRef]

203. Kaludercic, N.; Giorgio, V. The dual function of reactive oxygen/nitrogen species in bioenergetics and cell death: The role of ATP synthase. Oxid. Med. Cell. Longev. 2016, 2016, 3869610. [CrossRef]

204. Koskenkorva-Frank, T.S.; Weiss, G.; Koppenol, W.H.; Burckhardt, S. The complex interplay of iron metabolism, reactive oxygen species, and reactive nitrogen species: Insights into the potential of various iron therapies to induce oxidative and nitrosative stress. Free Radic. Biol. Med. 2013, 65, 1174-1194. [CrossRef]

205. Inoue, H.; Hanawa, N.; Katsumata, S.I.; Katsumata-Tsuboi, R.; Takahashi, N.; Uehara, M. Iron deficiency induces autophagy and activates Nrf2 signal through modulating p62/SQSTM. Biomed. Res. 2017, 38, 343-350. [CrossRef]

206. Tsutsui, H.; Kinugawa, S.; Matsushima, S. Mitochondrial oxidative stress and dysfunction in myocardial remodelling. Cardiovasc. Res. 2009, 81, 449-456. [CrossRef]

207. Toblli, J.E.; Cao, G.; Rivas, C.; Giani, J.F.; Dominici, F.P. Intravenous iron sucrose reverses anemia-induced cardiac remodeling, prevents myocardial fibrosis, and improves cardiac function by attenuating oxidative/nitrosative stress and inflammation. Int. J. Cardiol. 2016, 212, 84-91. [CrossRef]

208. Paterek, A.; Kępska, M.; Sochanowicz, B.; Chajduk, E.; Kołodziejczyk, J.; Polkowska-Motrenko, H.; Kruszewski, M.; Leszek, P.; Mackiewicz, U.; Mączewski, M. Beneficial effects of intravenous iron therapy in a rat model of heart failure with preserved systemic iron status but depleted intracellular cardiac stores. Sci. Rep. 2018, 8, 15758. [CrossRef]

209. Inserte, J.; Barrabés, J.A.; Aluja, D.; Otaegui, I.; Bañeras, J.; Castellote, L.; Sánchez, A.; Rodríguez-Palomares, J.F.; Pineda, V.; Miró-Casas, E.; et al. Implications of Iron Deficiency in STEMI Patients and in a Murine Model of Myocardial Infarction. JACC Basic Transl. Sci. 2021, 6, 567-580. [CrossRef]

210. Knutson, M.D.; Walter, P.B.; Ames, B.N.; Viteri, F.E. Both iron deficiency and daily iron supplements increase lipid peroxidation in rats. J. Nutr. 2000, 130, 621-628. [CrossRef]

211. Bhandari, S. Impact of intravenous iron on cardiac and skeletal oxidative stress and cardiac mitochondrial function in experimental uraemia chronic kidney disease. Front. Biosci._Landmark 2021, 26, 442-464. [CrossRef] 
212. Wong, A.-P.; Niedzwiecki, A.; Rath, M. Myocardial energetics and the role of micronutrients in heart failure: A critical review. Am. J. Cardiovasc. Dis. 2016, 6, 81-92.

213. Rineau, E.; Gaillard, T.; Gueguen, N.; Procaccio, V.; Henrion, D.; Prunier, F.; Lasocki, S. Iron deficiency without anemia is responsible for decreased left ventricular function and reduced mitochondrial complex I activity in a mouse model. Int. J. Cardiol. 2018, 266, 206-212. [CrossRef]

214. Naito, Y.; Tsujino, T.; Matsumoto, M.; Sakoda, T.; Ohyanagi, M.; Masuyama, T. Adaptive response of the heart to long-term anemia induced by iron deficiency. Am. J. Physiol.-Heart Circ. Physiol. 2009, 296, 585-593. [CrossRef]

215. Tanne, Z.; Coleman, R.; Nahir, M.; Shomrat, D.; Finberg, J.P.M.; Youdim, M.B.H. Ultrastructural and cytochemical changes in the heart of iron-deficient rats. Biochem. Pharmacol. 1994, 47, 1759-1766. [CrossRef]

216. Kobak, K.A.; Radwańska, M.; Dzięgała, M.; Kasztura, M.; Josiak, K.; Banasiak, W.; Ponikowski, P.; Jankowska, E.A. Structural and functional abnormalities in iron-depleted heart. Heart Fail. Rev. 2019, 24, 269-277. [CrossRef]

217. Chung, Y.J.; Luo, A.; Park, K.C.; Loonat, A.A.; Lakhal-Littleton, S.; Robbins, P.A.; Swietach, P. Iron-deficiency anemia reduces cardiac contraction by downregulating RyR2 channels and suppressing SERCA pump activity. JCI Insight 2019, 4, e125618. [CrossRef]

218. Martens, P.; Verbrugge, F.H.; Nijst, P.; Dupont, M.; Mullens, W. Limited contractile reserve contributes to poor peak exercise capacity in iron-deficient heart failure. Eur. J. Heart Fail. 2018, 20, 806-808. [CrossRef]

219. Núñez, J.; Miñana, G.; Cardells, I.; Palau, P.; Llàcer, P.; Fácila, L.; Almenar, L.; López-Lereu, M.P.; Monmeneu, J.V.; Amiguet, M.; et al. Noninvasive Imaging Estimation of Myocardial Iron Repletion Following Administration of Intravenous Iron: The Myocardial-IRON Trial. J. Am. Heart Assoc. 2020, 9, e014254. [CrossRef]

220. Santas, E.; Miñana, G.; Cardells, I.; Palau, P.; Llàcer, P.; Fácila, L.; Almenar, L.; López-Lereu, M.P.; Monmeneu, J.V.; Sanchis, J.; et al Short-term changes in left and right systolic function following ferric carboxymaltose: A substudy of the Myocardial-IRON trial. ESC Heart Fail. 2020, 7, 4222-4230. [CrossRef]

221. Toblli, J.E.; Di Gennaro, F.; Rivas, C. Changes in echocardiographic parameters in iron deficiency patients with heart failure and chronic kidney disease treated with intravenous iron. Heart Lung Circ. 2015, 24, 686-695. [CrossRef]

222. Usmanov, R.I.; Zueva, E.B.; Silverberg, D.S.; Shaked, M. Intravenous iron without erythropoietin for the treatment of iron deficiency anemia in patients with moderate to severe congestive heart failure and chronic kidney insufficiency. J. Nephrol. 2008, 21, 2236-2242.

223. Gaber, R.; Kotb, N.A.; Ghazy, M.; Nagy, H.M.; Salama, M.; Elhendy, A. Tissue doppler and strain rate imaging detect improvement of myocardial function in iron deficient patients with congestive heart failure after Iron replacement therapy. Echocardiography 2012, 29, 13-18. [CrossRef] [PubMed]

224. Núñez, J.; Monmeneu, J.V.; Mollar, A.; Núñez, E.; Bodí, V.; Miñana, G.; García-Blas, S.; Santas, E.; Agüero, J.; Chorro, F.J.; et al Left ventricular ejection fraction recovery in patients with heart failure treated with intravenous iron: A pilot study. ESC Heart Fail. 2016, 3, 293-298. [CrossRef] [PubMed]

225. Martens, P.; Verbrugge, F.; Nijst, P.; Dupont, M.; Tang, W.H.W.; Mullens, W. Impact of Iron Deficiency on Response to and Remodeling After Cardiac Resynchronization Therapy. Am. J. Cardiol. 2017, 119, 65-70. [CrossRef] [PubMed]

226. Lacour, P.; Dang, P.L.; Morris, D.A.; Parwani, A.S.; Doehner, W.; Schuessler, F.; Hohendanner, F.; Heinzel, F.R.; Stroux, A.; Tschoepe, C.; et al. The effect of iron deficiency on cardiac resynchronization therapy: Results from the RIDE-CRT Study. ESC Heart Fail. 2020, 7, 1072-1084. [CrossRef] [PubMed]

227. Nijst, P.; Martens, P.; Mullens, W. Heart Failure with Myocardial Recovery-The Patient Whose Heart Failure Has Improved: What Next? Prog. Cardiovasc. Dis. 2017, 60, 226-236. [CrossRef] [PubMed]

228. Chang, H.C.; Shapiro, J.S.; Ardehali, H. Getting to the "heart" of Cardiac Disease by Decreasing Mitochondrial Iron. Circ. Res. 2016, 119, 1164-1166. [CrossRef] [PubMed]

229. Sawicki, K.T.; Shang, M.; Wu, R.; Chang, H.C.; Khechaduri, A.; Sato, T.; Kamide, C.; Liu, T.; Naga Prasad, S.V.; Ardehali, H. Increased Heme Levels in the Heart Lead to Exacerbated Ischemic Injury. J. Am. Heart Assoc. 2015, 4, e002272. [CrossRef]

230. Khechaduri, A.; Bayeva, M.; Chang, H.C.; Ardehali, H. Heme levels are increased in human failing hearts. J. Am. Coll. Cardiol. 2013, 61, 1884-1893. [CrossRef]

231. Mancini, D.M.; Walter, G.; Reichek, N.; Lenkinski, R.; McCully, K.K.; Mullen, J.L.; Wilson, J.R. Contribution of skeletal muscle atrophy to exercise intolerance and altered muscle metabolism in heart failure. Circulation 1992, 85, 1364-1373. [CrossRef]

232. Stugiewicz, M.; Tkaczyszyn, M.; Kasztura, M.; Banasiak, W.; Ponikowski, P.; Jankowska, E.A. The influence of iron deficiency on the functioning of skeletal muscles: Experimental evidence and clinical implications. Eur. J. Heart Fail. 2016, 18, 762-773. [CrossRef]

233. Haas, J.D.; Brownlie IV, T. Iron deficiency and reduced work capacity: A critical review of the research to determine a causal relationship. J. Nutr. 2001, 131, 676S-690S. [CrossRef]

234. Finch, C.A.; Miller, L.R.; Inamdar, A.R.; Person, R.; Seiler, K.; Mackler, B. Iron deficiency in the rat. Physiological and biochemical studies of muscle dysfunction. J. Clin. Invest. 1976, 58, 447-453. [CrossRef]

235. Rineau, E.; Gueguen, N.; Procaccio, V.; Geneviève, F.; Reynier, P.; Henrion, D.; Lasocki, S. Iron deficiency without anemia decreases physical endurance and mitochondrial complex i activity of oxidative skeletal muscle in the mouse. Nutrients $\mathbf{2 0 2 1}$ 13, 1056. [CrossRef] 
236. Burden, R.J.; Morton, K.; Richards, T.; Whyte, G.P.; Pedlar, C.R. Is iron treatment beneficial in, irondeficient but nonanaemic (IDNA) endurance athletes? A systematic review and metaanalysis. Br. J. Sports Med. 2015, 49, 1389-1397. [CrossRef]

237. Barrientos, T.; Laothamatas, I.; Koves, T.R.; Soderblom, E.J.; Bryan, M.; Moseley, M.A.; Muoio, D.M.; Andrews, N.C. Metabolic Catastrophe in Mice Lacking Transferrin Receptor in Muscle. EBioMedicine 2015, 2, 1705-1717. [CrossRef]

238. Charles-Edwards, G.; Amaral, N.; Sleigh, A.; Ayis, S.; Catibog, N.; McDonagh, T.; Monaghan, M.; Amin-Youssef, G.; Kemp, G.J.; Shah, A.M.; et al. Effect of Iron Isomaltoside on Skeletal Muscle Energetics in Patients with Chronic Heart Failure and Iron Deficiency: FERRIC-HF II Randomized Mechanistic Trial. Circulation 2019, 139, 2386-2398. [CrossRef]

239. Forbes, J.M.; Thorburn, D.R. Mitochondrial dysfunction in diabetic kidney disease. Nat. Rev. Nephrol. 2018, 14, 291-312. [CrossRef]

240. Thévenod, F.; Lee, W.K.; Garrick, M.D. Iron and Cadmium Entry Into Renal Mitochondria: Physiological and Toxicological Implications. Front. Cell Dev. Biol. 2020, 8, 848. [CrossRef]

241. Van Swelm, R.P.L.; Wetzels, J.F.M.; Swinkels, D.W. The multifaceted role of iron in renal health and disease. Nat. Rev. Nephrol. 2020, 16, 77-98. [CrossRef]

242. Del Greco, F.M.; Foco, L.; Pichler, I.; Eller, P.; Eller, K.; Benyamin, B.; Whitfield, J.B.; Pramstaller, P.P.; Thompson, J.R.; Pattaro, C.; et al. Serum iron level and kidney function: A Mendelian randomization study. Nephrol. Dial. Transplant. 2017, 32, 273-278. [CrossRef]

243. El-Shimi, M.S.; El-Farrash, R.A.; Ismail, E.A.; El-Safty, A.; Nada, A.S.; El-Gamel, O.A.; Salem, Y.M.; Shoukry, S.M. Renal functional and structural integrity in infants with iron deficiency anemia: Relation to oxidative stress and response to iron therapy. Pediatr. Nephrol. 2015, 30, 1835-1842. [CrossRef]

244. Toblli, J.E.; Lombraña, A.; Duarte, P.; Di Gennaro, F. Intravenous Iron Reduces NT-Pro-Brain Natriuretic Peptide in Anemic Patients With Chronic Heart Failure and Renal Insufficiency. J. Am. Coll. Cardiol. 2007, 50, 1657-1665. [CrossRef]

245. Ponikowski, P.; Filippatos, G.; Colet, J.C.; Willenheimer, R.; Dickstein, K.; Lüscher, T.; Gaudesius, G.; Von Eisenhart Rothe, B.; Mori, C.; Greenlaw, N.; et al. The impact of intravenous ferric carboxymaltose on renal function: An analysis of the FAIR-HF study. Eur. J. Heart Fail. 2015, 17, 329-339. [CrossRef]

246. Stöhr, R.; Sandstede, L.; Heine, G.H.; Marx, N.; Brandenburg, V. High-Dose Ferric Carboxymaltose in Patients With HFrEF Induces Significant Hypophosphatemia. J. Am. Coll. Cardiol. 2018, 71, 2270-2271. [CrossRef]

247. Courbon, G.; Martinez-Calle, M.; David, V. Simultaneous management of disordered phosphate and iron homeostasis to correct fibroblast growth factor 23 and associated outcomes in chronic kidney disease. Curr. Opin. Nephrol. Hypertens. 2020, 29, 359-366. [CrossRef]

248. Stöhr, R.; Schuh, A.; Heine, G.H.; Brandenburg, V. FGF23 in cardiovascular disease: Innocent bystander or active mediator? Front. Endocrinol. 2018, 9, 351. [CrossRef]

249. Lanser, L.; Fuchs, D.; Kurz, K.; Weiss, G. Physiology and inflammation driven pathophysiology of iron homeostasis-mechanistic insights into anemia of inflammation and its treatment. Nutrients 2021, 13, 3732. [CrossRef]

250. Van der Wal, H.H.; Beverborg, N.G.; ter Maaten, J.M.; Vinke, J.S.J.; de Borst, M.H.; van Veldhuisen, D.J.; Voors, A.A.; van der Meer, P. Fibroblast growth factor 23 mediates the association between iron deficiency and mortality in worsening heart failure. Eur. J. Heart Fail. 2020, 22, 903-906. [CrossRef] [PubMed]

251. Cherayil, B.J. Iron and immunity: Immunological consequences of iron deficiency and overload. Arch. Immunol. Ther. Exp. 2010, 58, 407-415. [CrossRef] [PubMed]

252. Weiss, G. Iron and Immunity: A Double-Edged Sword. Eur. J. Clin. Investig. 2002, 32, 70-78. [CrossRef] [PubMed]

253. Ward, R.J.; Crichton, R.R.; Taylor, D.L.; Della Corte, L.; Srai, S.K.; Dexter, D.T. Iron and the immune system. J. Neural Transm. 2011, 118, 315-328. [CrossRef]

254. Cronin, S.J.F.; Woolf, C.J.; Weiss, G.; Penninger, J.M. The Role of Iron Regulation in Immunometabolism and Immune-Related Disease. Front. Mol. Biosci. 2019, 6, 116. [CrossRef]

255. Howden, A.J.M.; Hukelmann, J.L.; Brenes, A.; Spinelli, L.; Sinclair, L.V.; Lamond, A.I.; Cantrell, D.A. Quantitative analysis of T cell proteomes and environmental sensors during T cell differentiation. Nat. Immunol. 2019, 20, 1542-1554. [CrossRef]

256. Omara, F.O.; Blakley, B.R. The effects of iron deficiency and iron overload on cell-mediated immunity in the mouse. Br. J. Nutr. 1994, 72, 899-909. [CrossRef]

257. Spear, A.T.; Sherman, A.R. Iron deficiency alters DMBA-induced tumor burden and natural killer cell cytotoxicity in rats. J. Nutr. 1992, 122, 46-55. [CrossRef]

258. Pagani, A.; Nai, A.; Corna, G.; Bosurgi, L.; Rovere-Querini, P.; Camaschella, C.; Silvestri, L. Low hepcidin accounts for the proinflammatory status associated with iron deficiency. Blood 2011, 118, 736-746. [CrossRef]

259. Shayganfard, M. Are Essential Trace Elements Effective in Modulation of Mental Disorders? Update and Perspectives. Biol. Trace Elem. Res. 2021, 1-28. [CrossRef]

260. Ferreira, A.; Neves, P.; Gozzelino, R. Multilevel impacts of iron in the brain: The cross talk between neurophysiological mechanisms, cognition, and social behavior. Pharmaceuticals 2019, 12, 126. [CrossRef]

261. Todorich, B.; Pasquini, J.M.; Garcia, C.I.; Paez, P.M.; Connor, J.R. Oligodendrocytes and myelination: The role of iron. Glia 2009, 57, 467-478. [CrossRef]

262. Kim, J.; Wessling-Resnick, M. Iron and mechanisms of emotional behavior. J. Nutr. Biochem. 2014, 25, 1101-1107. [CrossRef]

263. Belmaker, R.H.; Agam, G. Major Depressive Disorder. N. Engl. J. Med. 2008, 358, 55-68. [CrossRef]

264. Di Palo, K.E. Psychological Disorders in Heart Failure. Heart Fail. Clin. 2020, 16, 131-138. [CrossRef] 
265. Barandiarán Aizpurua, A.; Sanders-van Wijk, S.; Brunner-La Rocca, H.P.; Henkens, M.T.H.M.; Weerts, J.; Spanjers, M.H.A.; Knackstedt, C.; van Empel, V.P.M. Iron deficiency impacts prognosis but less exercise capacity in heart failure with preserved ejection fraction. ESC Heart Fail. 2021, 8, 1304-1313. [CrossRef]

266. Huang, K.W.; Bilgrami, N.L.; Hare, D.L. Iron Deficiency in Heart Failure Patients and Benefits of Iron Replacement on Clinical Outcomes Including Comorbid Depression. Heart Lung Circ. 2021. [CrossRef]

267. Vargas-Uricoechea, H.; Bonelo-Perdomo, A. Thyroid Dysfunction and Heart Failure: Mechanisms and Associations. Curr. Heart Fail. Rep. 2017, 14, 48-58. [CrossRef]

268. Razvi, S.; Jabbar, A.; Pingitore, A.; Danzi, S.; Biondi, B.; Klein, I.; Peeters, R.; Zaman, A.; Iervasi, G. Thyroid Hormones and Cardiovascular Function and Diseases. J. Am. Coll. Cardiol. 2018, 71, 1781-1796. [CrossRef]

269. Maldonado-Araque, C.; Valdés, S.; Lago-Sampedro, A.; Lillo-Muñoz, J.A.; Garcia-Fuentes, E.; Perez-Valero, V.; Gutierrez-Repiso, C.; Goday, A.; Urrutia, I.; Peláez, L.; et al. Iron deficiency is associated with Hypothyroxinemia and Hypotriiodothyroninemia in the Spanish general adult population: Di@bet.es study. Sci. Rep. 2018, 8, 6571. [CrossRef]

270. Beard, J.; Tobin, B.; Green, W. Evidence for thyroid hormone deficiency in iron-deficient anemic rats. J. Nutr. 1989, 119, 772-778. [CrossRef]

271. Crielaard, B.J.; Lammers, T.; Rivella, S. Targeting iron metabolism in drug discovery and delivery. Nat. Rev. Drug Discov. 2017, 16, 400-423. [CrossRef]

272. Sheetz, M.; Barrington, P.; Callies, S.; Berg, P.H.; McColm, J.; Marbury, T.; Decker, B.; Dyas, G.L.; Truhlar, S.M.E.; Benschop, R.; et al. Targeting the hepcidin-ferroportin pathway in anaemia of chronic kidney disease. Br. J. Clin. Pharmacol. 2019, 85, 935-948. [CrossRef]

273. Crugliano, G.; Serra, R.; Ielapi, N.; Battaglia, Y.; Coppolino, G.; Bolignano, D.; Bracale, U.M.; Pisani, A.; Faga, T.; Michael, A.; et al. Hypoxia-inducible factor stabilizers in end stage kidney disease: "Can the promise be kept"? Int. J. Mol. Sci. 2021, $22,12590$. [CrossRef] [PubMed]

274. Liu, J.; Zhang, A.; Hayden, J.C.; Bhagavathula, A.S.; Alshehhi, F.; Rinaldi, G.; Kontogiannis, V.; Rahmani, J. Roxadustat (FG-4592) treatment for anemia in dialysis-dependent (DD) and not dialysis-dependent (NDD) chronic kidney disease patients: A systematic review and meta-analysis. Pharmacol. Res. 2020, 155, 104747. [CrossRef] [PubMed]

275. Chen, H.; Cheng, Q.; Wang, J.; Zhao, X.; Zhu, S. Long-term efficacy and safety of hypoxia-inducible factor prolyl hydroxylase inhibitors in anaemia of chronic kidney disease: A meta-analysis including 13,146 patients. J. Clin. Pharm. Ther. 2021, 46, 999-1009. [CrossRef] [PubMed]

276. Provenzano, R.; Besarab, A.; Wright, S.; Dua, S.; Zeig, S.; Nguyen, P.; Poole, L.; Saikali, K.G.; Saha, G.; Hemmerich, S.; et al. Roxadustat (FG-4592) versus epoetin alfa for anemia in patients receiving maintenance hemodialysis: A phase 2, randomized, 6- to 19-week, open-label, active-comparator, dose-ranging, safety and exploratory efficacy study. Am. J. Kidney Dis. 2016, 67, 912-924. [CrossRef]

277. Haase, V.H. HIF-prolyl hydroxylases as therapeutic targets in erythropoiesis and iron metabolism. Hemodial. Int. 2017, 21, S110-S124. [CrossRef] [PubMed]

278. Dalen, D.H.; Kragten, J.A.; Emans, M.E.; Ofwegen-Hanekamp, C.E.E.; Klaarwater, C.C.R.; Spanjers, M.H.A.; Hendrick, R.; Deursen, C.T.B.M.; Brunner-La Rocca, H. Acute heart failure and iron deficiency: A prospective, multicentre, observational study. ESC Heart Fail. 2021. [CrossRef]

279. Yilmaz, B.; Li, H. Gut microbiota and iron: The crucial actors in health and disease. Pharmaceuticals 2018, 11, 98. [CrossRef]

280. Rusu, I.G.; Suharoschi, R.; Vodnar, D.C.; Pop, C.R.; Socaci, S.A.; Vulturar, R.; Istrati, M.; Moroșan, I.; Fărcaș, A.C.; Kerezsi, A.D.; et al. Iron supplementation influence on the gut microbiota and probiotic intake effect in iron deficiency-A literature-based review. Nutrients 2020, 12, 1993. [CrossRef]

281. Lee, T.; Clavel, T.; Smirnov, K.; Schmidt, A.; Lagkouvardos, I.; Walker, A.; Lucio, M.; Michalke, B.; Schmitt-Kopplin, P.; Fedorak, R.; et al. Oral versus intravenous iron replacement therapy distinctly alters the gut microbiota and metabolome in patients with IBD. Gut 2016, 66, 863-871. [CrossRef] 